\title{
Use of Mature miRNA Strand Selection in miRNAs Families in Cervical Cancer Development
}

\author{
Angelica Judith Granados-López ${ }^{1,2}$, José Luis Ruiz-Carrillo ${ }^{1}$, Luis Steven Servín-González ${ }^{3}$, \\ José Luis Martínez-Rodríguez ${ }^{1}$, Claudia Araceli Reyes-Estrada ${ }^{4}$, \\ Rosalinda Gutiérrez-Hernández ${ }^{4}$ and Jesús Adrián López ${ }^{1,2, *}$ \\ 1 Laboratorio de microRNAs, Unidad Académica de Ciencias Biológicas, Universidad Autónoma de Zacateacs, \\ Av. Preparatoria S/N, Zacatecas 98066, Mexico; agranadosjudith@gmail.com (A.J.G.-L.); \\ jocaru2012@gmail.com (J.L.R.-C.); joseluis_mtzrdz_qfb@hotmail.com (J.L.M.-R.) \\ 2 Doctorado en Ciencias Básicas, Universidad Autónoma de Zacateacs, Av. Preparatoria S/N, Campus II, \\ Zacatecas 98066, Mexico \\ 3 School of Life Sciences, Gibbert Hill Campus, University of Warwick, Coventry CV47AL, UK; \\ L.Servin-Gonzalez@warwick.ac.uk \\ 4 Doctorado en Ciencias Básicas en la Especialidad en Farmacología Médica y Molecular de la Unidad \\ Académica de Medicina Humana y Ciencias de la Salud de la Universidad Autónoma de Zacateacas, \\ Campus Siglo XXI, Kilómetro 6, Ejido la Escondida, Zacatecas CP 98160, Mexico; \\ c_reyes13@yahoo.com.mx (C.A.R.-E.); rosalindagh@hotmail.com (R.G.-H.) \\ * Correspondence: jalopez@uaz.edu.mx; Tel.: +52-492-149-2648
}

Academic Editor: Y-h. Taguchi

Received: 10 January 2017; Accepted: 8 February 2017; Published: 14 February 2017

\begin{abstract}
Aberrant miRNA expression is well recognized as a cancer hallmark, nevertheless miRNA function and expression does not always correlate in patients tissues and cell lines studies. In addition to this issue, miRNA strand usage conduces to increased cell signaling pathways modulation diversifying cellular processes regulation. In cervical cancer, 20 miRNA families are involved in carcinogenesis induction and development to this moment. These families have $5 p$ and $3 p$ strands with different nucleotide (nt) chain sizes. In general, mature $5 p$ strands are larger: two miRNAs of $24 \mathrm{nt}, 24$ miRNAs of $23 \mathrm{nt}, 35$ miRNAs of $22 \mathrm{nt}$ and three miRNAs of $21 \mathrm{nt}$. On the other hand, the $3 p$ strands lengths observed are: seven miRNAs of $23 \mathrm{nt}, 50$ miRNAs of $22 \mathrm{nt}$, six miRNAs of $21 \mathrm{nt}$ and four miRNAs of $20 \mathrm{nt}$. Based on the analysis of the 20 miRNA families associated with cervical cancer, $673 p$ strands and $655 p$ strands are selected suggesting selectivity and specificity mechanisms regulating cell processes like proliferation, apoptosis, migration, invasion, metabolism and Warburg effect. The insight reviewed here could be used in the miRNA based therapy, diagnosis and prognosis approaches.
\end{abstract}

Keywords: miRNA families; strand 5p; strand 3p; cervical cancer

\section{Introduction}

Genes are classified in families based on three characteristics, their phylogenetic origin, sequence similitude and possible functional homology [1], sharing several mechanisms of regulation. Most families have evolutionary conservation implying an important biological function [1,2]. Members of different miRNA families have evolved to target a diverse set of transcripts by mechanisms including arm switching, seed shifts, insertions and nucleotide editing of mature transcripts, giving rise to different seed sequences and hence altered target specificities [3]. The members of the different miRNA families present overlapping mRNAs target and tissue specificity [4]. Interestingly, the miRNAs from a family do not express equally, neither do the $5 p$ nor $3 p$ strand 
of a pre-miRNA [2,5-7]. Gene regulation by miRNAs acquired a complexity achieved by several factors like the type of promoter that determines the regulation of mRNAs targets [8], RNA edition [9], RNA base addition [10,11], RNA slicing [12], and miRNA strand selection [13], among others. miRNA strand maturation is a complex process consisting of two cuts, sequence thermodynamic instability and protein interactions. The $5 \mathrm{p}$ strand is produced by the cut of the microprocessor (Drosha and DGCR8) [14] and other proteins that interact with this complex like, p68, p72, Smads, p53 and ER $\alpha$. Other proteins directly interact with the structure and sequence of pri-miR and pre-miR, like hnRNP A1 and KSRP that bind to and increase pri-miRNA and pre-miRNA dicing in contrast to Lin 28 that inhibits the cuts [15]. The 3p strand is formed by Dicer dicing and its activity is favored by TRBP and PACT interaction. Protein post-translational modifications contribute to miRNA cropping. Phosphorylation of TRBP via MAPK increases enzymatic function of Dicer as well as hydroxylation by type I collagen prolyl-4-hydroxylase stabilizes Ago 2 [16]. Thermodynamic strand selection obeys to GC and AU content in $5^{\prime}$ of $5 p$ and $3 p$ strand, considering that a high content of AU in the $5^{\prime}$ of $3 p$ strand is going to be selected over $5 p$ strand and vice versa. Protein participation in miRNA strand selection could override thermodynamic properties of miRNA sequence. However, the combination of both mechanisms is evolutionarily conserved and used to select miRNA strands conducing to gene expression regulation. The selection of miRNA strand is dependent of cell type, tissue and stimulus [14]. Sequence conservation and RNA binding-proteins evolved together to achieve a final fine-tuning gene regulation in different cells and tissues. Cervical cancer possesses particular cell types with specific differentiation patterns as a result of a special and unique gene expression. Previously, we analyzed 53 miRNAs reported in the literature associated with cervical cancer progression based on constant expression reported [17] and from these genes we further studied the families of miRNAs and the cell signaling pathways associated with 21 miRNA families grouped in 20 clusters [18] without noticing strand participation. Many of the studies reviewed did not specify the mature strand used in the investigation, while the star strand is almost never studied. Conventionally, mature miRNA strand performing silencing is recognized as guide strand and the other one as star $\left(^{*}\right)$ strand or passenger strand, which is usually degraded. However, guide and star strands have hundreds of potential targets and every family member has a particular mature miRNA expression that determines differential or complementary functions that regulate cell processes. In this review, we focused on strand selection of 20 families of miRNAs involved in cervical cancer based on expression and known function with the objective to uncover the importance of strand selection in cervical cancer. We investigated mature miRNA used in the studies reported and we observed a constant expression of miRNA guide strand from some members of miRNA families, however, for miR-10a, miR-15a, miR-16, and miR-200a, expression of both guide and star strands was noticed. Importantly, miRNA star strand expression of the rest of members of the 20 families associated in cervical cancer is currently unknown. Additionally, we performed miRNA families sequences alignments to analyze sequence conservation and nt chain length observing a great variation in sequence homology and nt chain size among families members supporting differential target gene regulation.

\section{Anti-Oncogenic miR-1 Family Participates in Cervical Cancer}

miRNA-1 (miR-1) family is formed by miR-1-1, miR-1-2 and miR-206; nevertheless, it should be noted that miR-1-1 and miR-1-2 originate the same mature sequence, miR-1-3p. It is important to remark this particular issue because the pri-miR and pre-miR of miR-1 sequence and chromosome localization are different, therefore, biogenesis regulation could be singular for each one. miR-1-1 and miR-1-2 are localized in chromosome 20 and 18, respectively, while miR-206 is found in chromosome $6[19,20]$. Interestingly, despite sequence similarity, it has been shown that $5 p$ strand of miR-1-2 and miR-206 is not expressed therefore it does not appear in Figure 1 or Figure 2, in contrast to $3 p$ strand of miR-1 (Figure 3). miR-1-1-3p and miR-1-2-3p have 100\% sequence similarity while miR-206 has four different bases (Figure 3). Identification of $5 p$ strand of miR-1-1 has been reported in 10 experiments achieving 37 reads while $3 p$ strand has more than 759,000 reads [20]. miR-1-3p has been 
shown down-regulated in cervical cancer versus normal tissue [17] and its overexpression diminishes proliferation, tumor growth and promotes apoptosis by glucose-6-phosphate dehydrogenase (G6PD) down-regulation [21] functioning as anti-oncomiR (Table 1).

Table 1. miRNAs families showing cervical cancer miRNA expression, function, chromosome localization, DNA strand, mature strand conservation, and nt chain sizes. ? = unknown, + DNA strand $=$ strand direction from $5^{\prime}$ to $3^{\prime},-$ DNA strand $=$ strand direction from $3^{\prime}$ to $5^{\prime}, \mathrm{C}=$ Conserved strand, $\mathrm{NC}=$ Not conserved strand, $\mathrm{A}=$ Anti-oncomiR, $\mathrm{O}=$ OncomiR, nts = nucleotides.

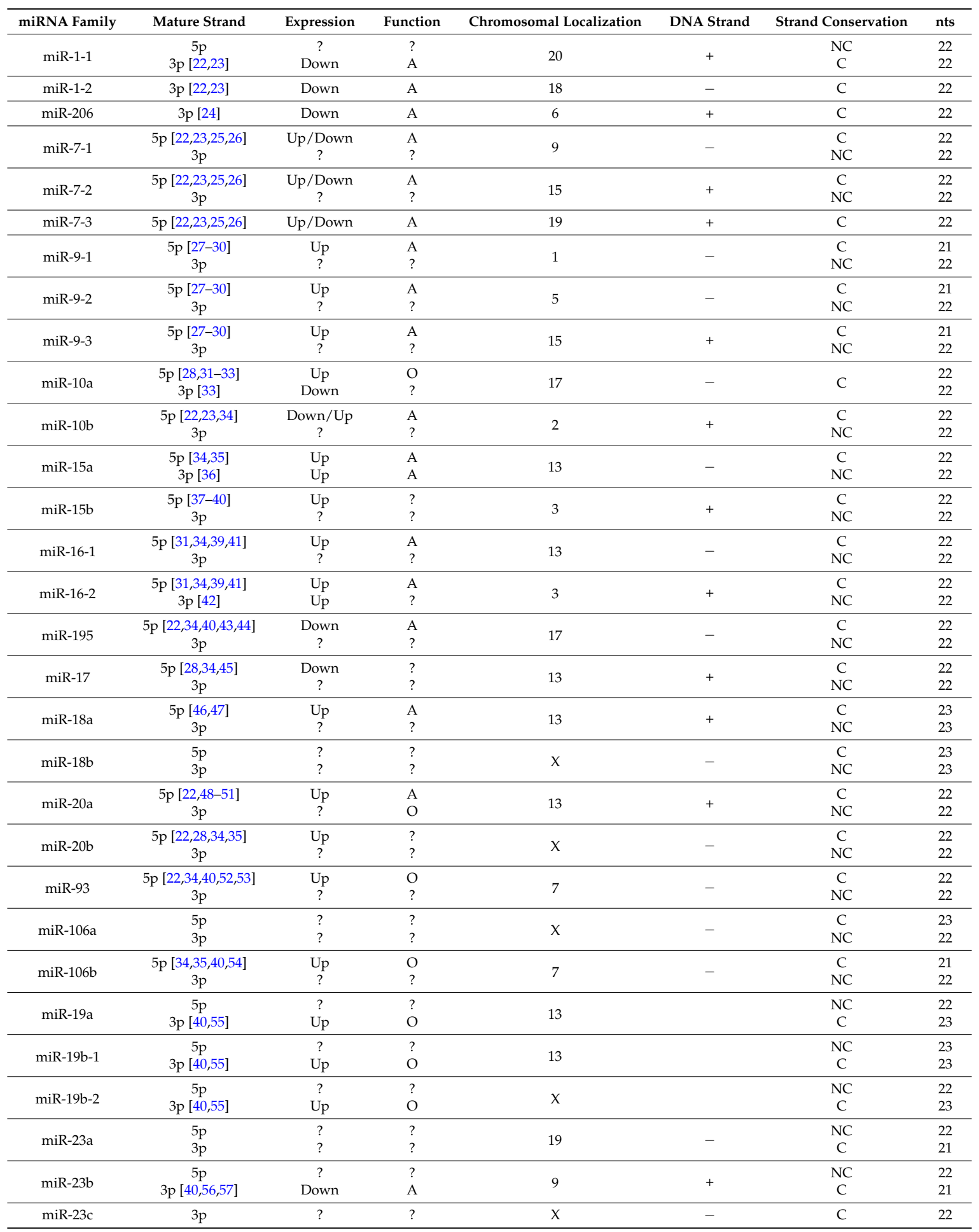


Table 1. Cont.

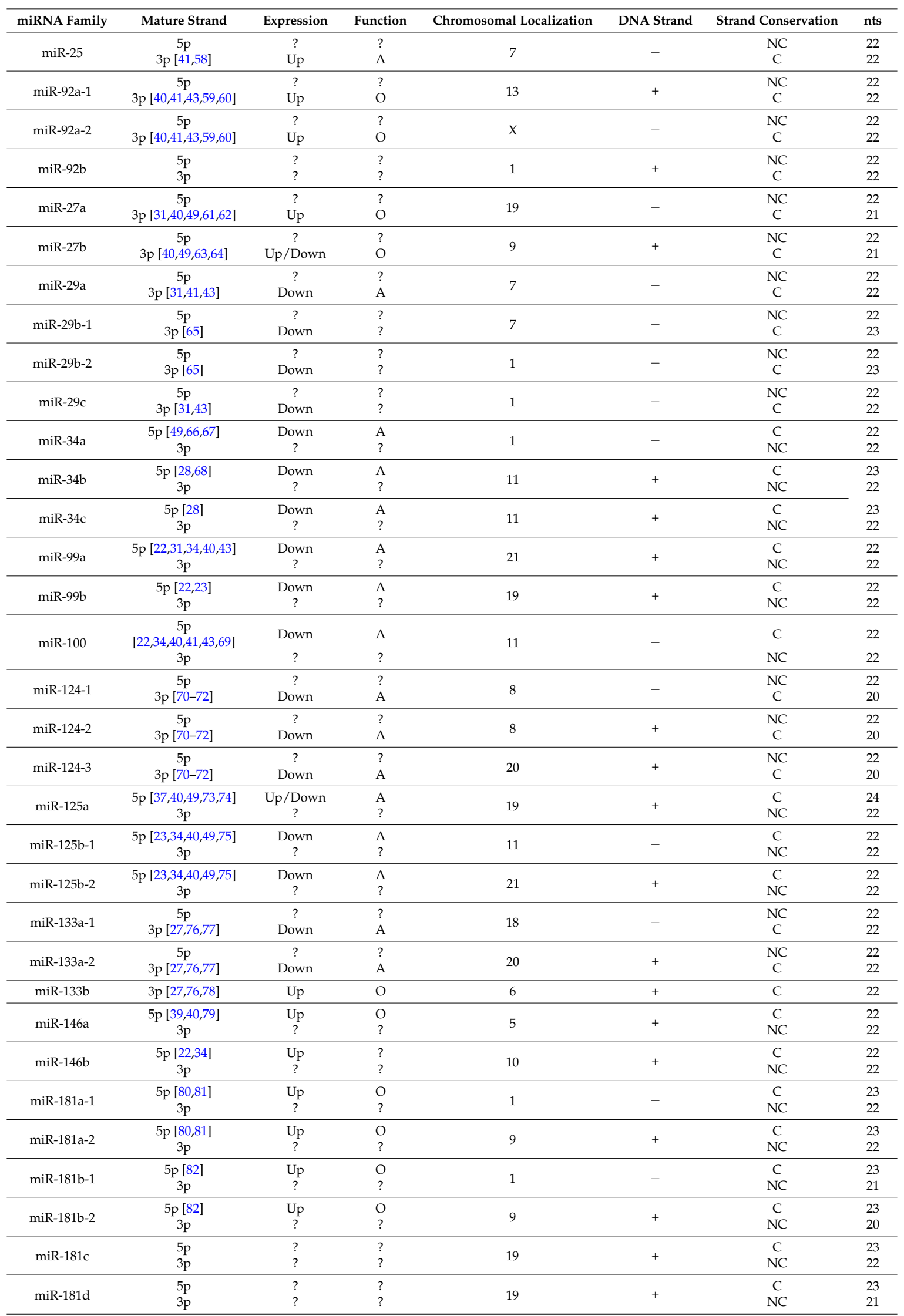


Table 1. Cont.

\begin{tabular}{|c|c|c|c|c|c|c|c|}
\hline miRNA Family & Mature Strand & Expression & Function & Chromosomal Localization & DNA Strand & Strand Conservation & nts \\
\hline miR-196a-1 & $5 p$ [83-85] & Up & $\mathrm{O}$ & 17 & - & $\mathrm{C}$ & 22 \\
\hline \multirow{2}{*}{ miR-196a-2 } & $5 p$ [83-85] & Up & $\mathrm{O}$ & & & C & 22 \\
\hline & $3 p$ & $?$ & $?$ & 12 & + & NC & 22 \\
\hline \multirow{2}{*}{ miR-196b } & $5 p[57,86]$ & Down & A & \multirow[t]{2}{*}{7} & & C & 22 \\
\hline & $3 p$ & $?$ & $?$ & & - & NC & 22 \\
\hline miR-200a & $5 p[40]$ & Up & $?$ & 1 & + & NC & 22 \\
\hline miR-200b & $3 p[88-90]$ & Up/Down & A & 1 & + & $\mathrm{C}$ & 22 \\
\hline \multirow{2}{*}{ miR-200c } & $5 p$ & $?$ & $?$ & \multirow[b]{2}{*}{12} & \multirow[b]{2}{*}{+} & NC & 22 \\
\hline & $3 p[34,37,40,49]$ & Up/Down & $\mathrm{O}$ & & & $\mathrm{C}$ & 23 \\
\hline
\end{tabular}

\section{3. miR-7 Family Participates in Cervical Cancer}

miR-7 family is formed by miR-7-1, miR-7-2 and miR-7-3 localized in chromosomes 9, 15 and 19, respectively. MiR-7-3-3p arm has not been annotated [20] (Figure 3). The 5p arms share 100\% similarity between family members, whereas $3 p$ strands differ in four nucleotides between them (Figure 1 ). The difference between $3 p$ strands of miR-7 family could lead to a distinct type of mature miRNA biogenesis selection conducing to specific target mRNA regulation that should be evaluated in cervical cancer progression. It is well known that a single nucleotide change in miRNAs could change target specificity [9]. Mature 5p strand of miR-7 is down-regulated in cervical cancer versus normal tissue and its overexpression inhibits the Focal Adhesion Kinase (FAK) and X-Linked Inhibitor of Apoptosis (XIAP) oncoproteins formation inducing apoptosis, inhibiting proliferation, migration and invasion [22,23]. On the contrary, two independent works show this miRNA as up-regulated in tumors versus normal tissue [24,25], suggesting that it functions like an oncogene. However, its function and expression do not correlate with cervical cancer progression [22,23]. In fact, miR-7 overexpression could be a signal to halt carcinogenesis process that is overridden by signals inducing cervical cancer development.

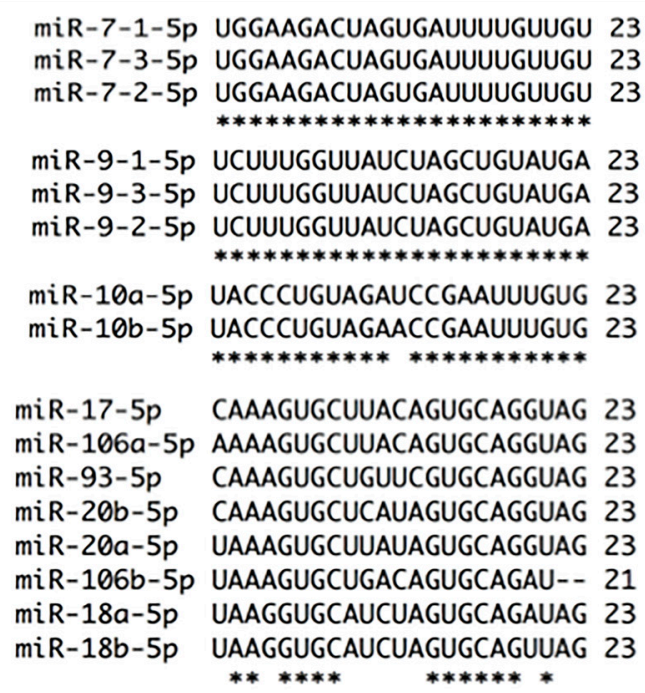

miR-34b-5p UAGGCAGUGUCAUUAGCUGAUUG- 23 miR-34c-5p -AGGCAGUGUAGUUAGCUGAUUGC 23 miR-34a-5p -UGGCAGUGUC-UUAGCUGGUUGU 22 ********* ***********

$m i R-181 b-2-5 p$ AACAUUCAUUGCUGUCGGUGGGU 23 miR-181d-5p AACAUUCAUUGUUGUCGGUGGU 23 miR-181b-1-5p AACAUUCAUUGCUGUCGGUGGGU 23 miR-181a-1-5p AACAUUCAACGCUGUCGGUGAGU 23 miR-181c-5p AACAUUCAAC-CUGUCGGUGAGU 22 miR-181a-2-5p AACAUUCAACGCUGUCGGUGAGU 23 *********

Figure 1. Alignments of miRNAs families by strand $5 p$ selection and nt chain sizes. Six miRNA families were chosen by strand selection and nt chain size. Almost all members of these families are $23 \mathrm{nt}$ in length, except miR-34a, and share high sequence conservation. miR-7 and miR-9 families have 100\% of homology, miR-10 family varies only in $1 \mathrm{nt}$, miR-181 family is dissimilar in $3 \mathrm{nt}$, miR-17 family has five different $\mathrm{nt}$, and miR-34 family presents six dissimilar nt. * at the bottom of the alignment indicates nt homology between family members. 


\section{Oncogenic miR-9 Family Participates in Cervical Cancer}

miR-9, another microRNA implicated in carcinogenesis [17], is localized in chromosomes 1,5 and 15 and generates transcripts for miRNA-9-1, miR-9-2 and miR-9-3, respectively. Each strand from the three members can be loaded on RNA-Induced Silencing Complex (RISC) machinery based on strands homology and conservation (Figures 1 and 3), suggesting a conserved and vast variety of mRNA targets involved in cancer progression. However, $5 p$ strand abundance is superior more than 174 times to $3 p$ strand [20]. In addition, $5 p$ strand has been detected in at least two independent works [26,27] while $3 p$ strand has not been detected in cervical cancer. miR-9 increase in squamous cervical cancer is associated with Human Papillomavuris E6 (HPV-E6) presence [28,29], however, in adenocarcinoma it has been reported as down-regulated by hypermethylation and its overexpression diminishes proliferation and migration via inhibition of Jak/STAT3 signaling activity through 3'UTR CKAP2, HSPC159, IL-6 and TC10 regulation [30]. We observe discrepancy between squamous and adenocarcinoma miR-9 expression from cervix, however, it is important to note that different cells and tissues from the same organ have distinctive miRNA expression and probably function as well.

\section{5. miR-10 Family Participates in Cervical Cancer}

miRNAs deregulation correlates with oncogenic or anti-oncogenic function such as the case of miR-10 family that is composed of miR-10a and miR-10b localized in chromosomes 17 and 2, respectively [20,31]. Interestingly, the members of this family have shown opposite expression [32] (Table 1). Additionally, $5 p$ and 3p strands of miR-10a have shown different expression [33] (Table 1). The seed sequence of miR-10a and miR-10b is identical, therefore it should be expected that they share similar transcript targets, however, they have different expression and function. miR-10a-5p shows a progressive increase through Steps 1 to 4 of carcinogenesis $[17,32,34,35]$ and induces colony formation, migration and invasion in HeLa, C-33A and SiHa cells by down-regulation of Cell Adhesion Molecule L1 Like (CHL1) and Phosphatase and Tensin Homolog PTEN via 3'UTR [36,37]. miR-10b-5p has been shown decreased in cervical cancer $[24,25]$ as well as in pre-malignant steps and its overexpression reduces proliferation and invasion via 3'UTR down-regulation of Homeobox A1 (HOXA1) [38]. It should be noted that $5 \mathrm{p}$ strand of miR-10a and miR-10b potentially regulate CHL1, PTEN and HOXA1 (Target Scan, mirnaorg.com and Diana-microt) based on $95.65 \%$ of similitude (Figure 1). $3 p$ strand of miR-10a and -b share $77 \%$ of sequence similarity (Figure 3), therefore mRNAs targets variability should increase diversifying the cellular pathways regulated by these strands.

\section{Oncogenic miR-15 Family Participates in Cervical Cancer}

miR-15 family is composed of miR-15a, miR-15b, miR-16 and miR-195 [39], localized in different genomic context (Table 1), hence their expression in cervical cancer development could be attributable to similar gene regulation achieved by cellular advantages acquired during carcinogenesis. In a similar fashion to miR-10 family, miR-15 family shows contradictory effects in cervical cancer progression, while miR-15a, miR-15b and miR-16 are shown overexpressed, miR-195 is down-regulated from Step 2 to 4 of carcinogenesis [17,35,40]. miR-15 and miR-16 overexpression inhibit proliferation, G1-S cycle transition in HeLa cells attenuating mTOR and p70S6K phosphorylation by down-regulation of Rictor inhibiting p62 a selective substrate for autophagy-lysosome degradation and increasing LC3-II conversion an autophagy gene-associated [41]. Interestingly, miR-15a-3p has a contrary function to miR-15a-5p, since the 3p strand triggers caspase $3 / 7$ activation and reduces HeLa cells viability through Bcl-XL via 3'UTR [42]. In relation to miR-16-1, it shows an inverse expression with Cyclin E1 mRNA in $\mathrm{SiHa}, \mathrm{HeLa}$ and CasKi cells, however, luciferase and protein data is missing [43]. Furthermore, miR-16-2-3p has been shown up-regulated in serum pointing out the role of miR-16 in cervical carcinogenesis [40]. On the other hand, miR-195 is shown down-regulated in cervical cancer and its overexpression inhibits proliferation, G1-S transition, migration and invasion through Cyclin 
D1, Cyclin D2, MYB proto-oncogene, transcription factor (MYB) and Smad 3 down-regulation via 3'UTR [44-47].

Since mature miRNA sequences of members of miR-15 family have shown expression differences, the effects on targets are expected to be different. As can be seen in Figure 2, seed sequence of $5 p$ strands is similar among family members, contrary to $3 p$ strand that is totally different between them (Figure 3). However, in 3p strand, there are six conserved nt between family members raising the possibility to regulate several targets taking count that miRNAs regulate mRNAs independently of seed sequence [48]. One point of miRNA regulation is the strand selection, thereby, while the guide strand is incorporated to Ago protein to form miRISC complex, * strand is degraded as a natural biogenesis process. Nevertheless, for several miRNAs, both strands are incorporated into miRISC complex and strand selection depends on tissue, cell type and proteins present [49,50]. In this respect, which strand is selected under different types of stress, such as cancer progression, has not been studied.

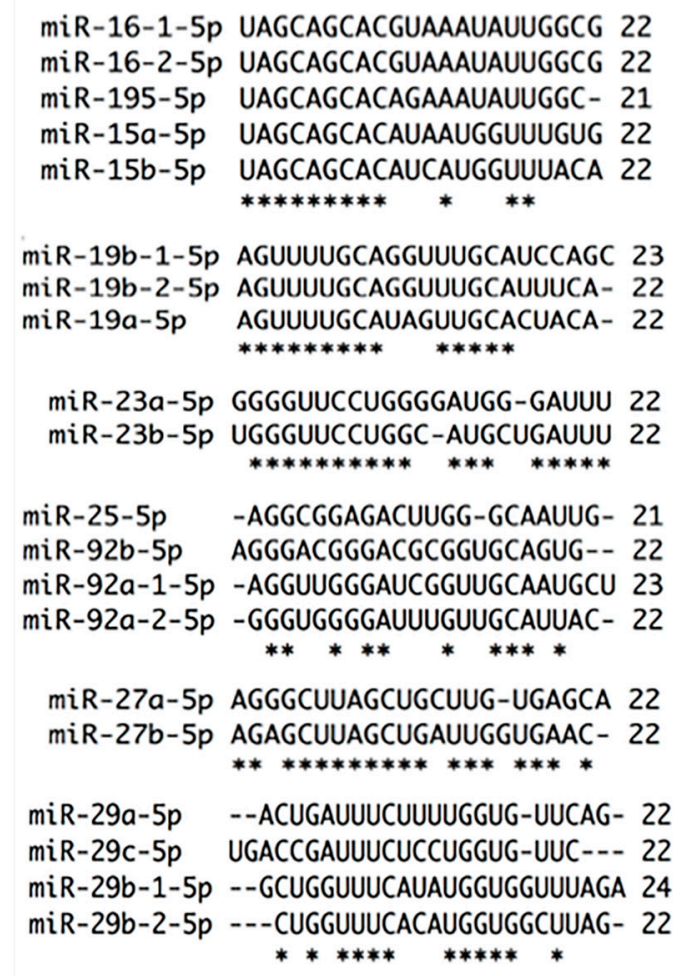

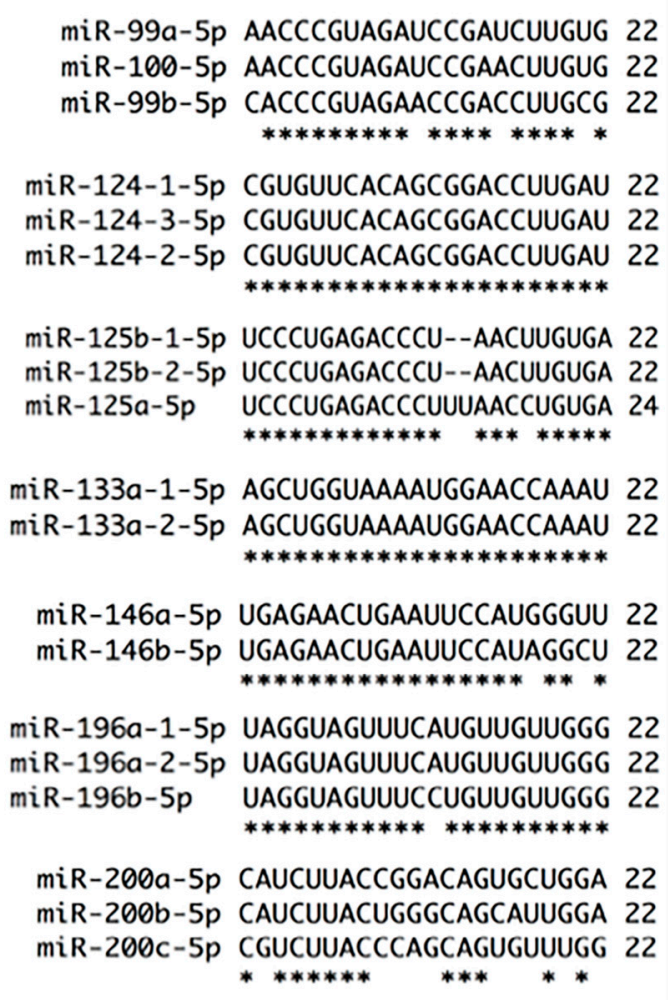

Figure 2. Alignments of miRNAs families by $5 p$ strand selection and nt chain sizes. Thirteen miRNA families were chosen by strand and nt chain sizes. Almost all members of these families are $22 \mathrm{nt}$ in length, except miR-195 (21 nt), miR-19b-1 (23 nt), miR-25 (21 nt), miR-92a-1 (23 nt), miR-29b-1 (24 nt), and miR-125a (24 nt). Of 13 miRNA families analyzed, only five use $5 \mathrm{p}$ arm as guide strand. miR-15 family shares $54.45 \%$, miR-99 family $81.81 \%$, miR-125 family $86.36 \%$, miR- 146 family $90.90 \%$ and $\mathrm{miR}-196$ 95.45\% strand conservation. The rest of the families use the strand $3 p$, therefore, they show less 5 p strand conservation. miR-19 family has $63.63 \%$, miR-23 family $77.27 \%$, miR-25 family $45.45 \%$, miR-27 family 72.72\%, miR-29 family $45.54 \%$, miR-124 100\%, miR-133 100\% and miR-200 family $72.72 \%$ conservation. * at the bottom of the alignment indicates nt homology between family members. 
miR-1-1-3p UGGAAUGUAAAGAAGUAUGUAU 22 miR-1-2-3p UGGAAUGUAAAGAAGUAUGUAU 22 miR-206-3p UGGAAUGUAAGGAAGUGUGUGG 22 *******************10

miR-7-1-3p CAACAAAUCACAGUCUGCCAUA 22 miR-7-2-3p CAACAAAUCCCAGUCUACCUAA 22 $* * * * * * * * * * * * * * * * * *$

miR-9-1-3p AUAAAGCUAGAUAACCGAAAGU 22 miR-9-3-3p AUAAAGCUAGAUAACCGAAAGU 22 miR-9-2-3p AUAAAGCUAGAUAACCGAAAGU 22 $* * * * * * * * * * * * * * * * * * * * * * * * *$

miR-10a-3p -CAAAUUCGUAUCUAGGGGAAUA 22 miR-10b-3p ACAGAUUCGAUUCUAGGGGAAU- 22 ********************1\%

miR-15b-3p CGAAUCAUUA-UU-UGCUGCUCUA 22 miR-16-2-3p CCAAU-AUUA-CUGUGCUGCUUUA 22 miR-195-3p CCAAU-AUUGGCUGUGCUGCUCC- 22 miR-16-1-3p CCAGU-AUUAACUGUGCUGCUGA- 22 miR-15a-3p CAGGCCAU--AUUGUGCUGCCUCA 22 * **********

miR-20a-3p ACUGCAUUAUGAGCACUUAAAG-- 22 miR-20b-5p ACUGUAGUAUGGGCACUUCCAG-- 22 miR-17-3p ACUGCAGUGAAGGCACUUGUAG-- 22 miR-93-3p ACUGCUGAGCUAGCACUUCCCG- 22 miR-106a-3p -CUGCAAUGUAAGCACUUCUUAC - 22 miR-106b-3p -CCGCACUGUGGGUACUUGCUGC- 22 miR-18a-3p ACUGCCCUAAGUGCUCCUUCUGG- 23 miR-18b-3p --UGCCCUAAAUGCCCCUUCUGGC 22

miR-92a-1-3p UaUUGCACUUGUCCCGGCCUGU 22 miR-92a-2-3p UAUUGCACUUGUCCCGGCCUGU 22 miR-92b-3p UAUUGCACUCGUCCCGGCCUCC 22 miR-25-3p CAUUGCACUUGUCUCGGUCUGA 22 $* * * * * * * * * * * * * * * *$

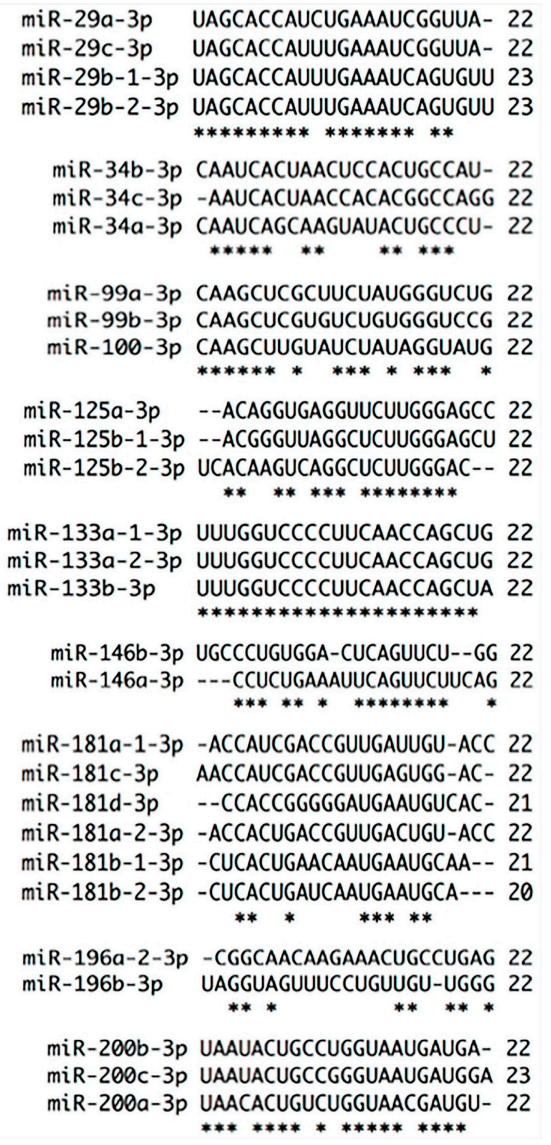

Figure 3. Alignments of miRNAs families by $3 p$ strand selection and nt chain sizes. Sixteen miRNA families were chosen by miRNA strand and nt chain sizes. Almost all members of these families are $22 \mathrm{nt}$ in length except miR-29b-1, miR-29b-2 (23 nt), miR-181b-1 (21 nt), miR-181b-2 (20 nt) and miR-200c (23 nt). Of 16 families analyzed, only five use 3p arm as guide strand. miR-1 family shares $81.81 \%$, miR-25 family $72.72 \%$, miR-29 family $77.27 \%$, miR-133 family $100 \%$ and miR-200 $72.72 \%$ strand conservation. The rest of the families use the strand $5 p$, therefore, they show less $3 p$ strand conservation. miR-7 family has $81.81 \%$, miR-9 family $100 \%$, miR-10 family $77.27 \%$, miR-15 family $45.45 \%$, miR-34 family $54.54 \%$, miR-99 family $68.18 \%$, miR-125 family $59.09 \%$, miR-146 family $54.54 \%$ and miR-196 family $36.36 \%$ strand conservation. * at the bottom of the alignment indicates nt homology between family members.

\section{Oncogenic miR-17 Family Participates in Cervical Cancer}

The members of miR-17 family have also shown differential expression patterns (Table 1), a characteristic shared with several miRNA families. miR-17 family is integrated by miR-17, miR-18a, miR-18b, miR-20a, miR-20b, miR-93, miR-106a and miR-106b. Most of the members of this family differ in mature sequence by $10 \mathrm{nt}$ [51] (Figures 1 and 3), implying a diverse function on mRNA targets regulation. In general, miR-17 family 5p strands have five different bases. miR-20a-5p and miR-20b-5p have only one different nucleotide in mature sequence as well as miR-17-5p and miR-106a-5p. miR-93-5p is the most dissimilar within the members of this family presenting three different bases with miR-20a-5p and miR-20b-5p, four with miR-17-5p and five with miR-106a-5p (Figure 1). 3p strands of the members of this family have 14 nucleotides of dissimilarity. miR-20a and miR-20b have five different bases; and miR-17-3p has six, seven and eight nucleotides different from miR-20b-3p, miR-20a-3p and miR-93-3p, respectively. miR-106a-3p has 10 dissimilar nt from miR-93-3p, nine from miR-20b-3p, eight with miR-17-3p and eight with miR-20a-3p (Figure 3). 
miR-17-5p has been shown down-regulated while miR-20a, miR-20b, miR-93, miR-106a and miR-106b are found up-regulated exhibiting important changes during cervical cancer progression [17,52]. miR-18a is up-regulated in HPV-related exosomes [53] and induces radiosensitivity in cells irradiated, reducing ATM and $\gamma-\mathrm{H} 2 \mathrm{AX}$ proteins, triggering apoptosis by caspase 3 activation and PARP cleaved [54]. miR-20a-5p up-regulates Tankyrase 2 (TNKS2) and down-regulates Autophagy Related 7 (ATG7), an essential protein for autophagy and transport from cytoplasmic to vacuole and Metallopeptidase Inhibitor 2 (TIMP2), a natural protein inhibitor of the matrix metalloproteinases, in a sequence dependent form reducing apoptosis and inducing colony formation, migration, and invasion [55,56]. miR-93 is increased from Step 1 to 4, augmenting proliferation and decreasing apoptosis through down-regulation of RAB11 Family Interacting Protein 1 (RAB11FIP1), a protein involved in endocytic sorting, trafficking of proteins including integrin subunits and epidermal growth factor receptor (EGFR), and transport between the recycling endosome and the trans-Golgi network [57]. miR-106b is up-regulated in cervical cancer through TGF- $\beta 1$ eliciting migration by down-regulation of Disabled Homolog 2, Mitogen-Responsive Phosphoprotein (Drosophila) (DAB2) via $3^{\prime} \mathrm{UTR}$. DAB2 is a protein that binds to the SH3 domains of GRB2, an adaptor protein that couples tyrosine kinase receptors to SOS through its $\mathrm{C}$-terminal proline-rich sequences, and may thus modulate growth factor/Ras pathways by competing with SOS for binding to GRB2 [58]. In accordance with Pictar, MIRDB, and microrna.org TNKS2, ATM, ATG7, TIMP2 and RAB11FIP1 are potentially regulated by miR-17-5p, miR-106a-5p, miR-106b-5p, miR-93-5p and miR-20b-5p. This assumption is made for these genes, however, it is important to take into account that every miRNA potentially regulates more than 100 genes; therefore, experimental validation is imperative.

\section{8. miR-19 Family Participates in Cervical Cancer}

miR-19 family is composed of miR-19a, miR-19b-1, and miR-19b-2 [51]. Increased expression of $\mathrm{miR}-19 \mathrm{a} / \mathrm{b}$ is involved in cervical carcinogenesis [17] probably by Cullin 5 (CUL5) down-regulation [59]. The 3p arm from both miRNAs are recognized as the guide strand [20] and, as can be observed in Figure 4, these strands only have one different $n t$ between miR-19a and miR-19b in contrast with the $5 \mathrm{p}$ arms, which vary in more than $8 \mathrm{nt}$ (Figure 2). Based on sequence similarities, it is possible that all members of this family could regulate CUL5 and several additional genes. Nevertheless, the * strand could open a vast set of new and important mRNAs targets.

(a)

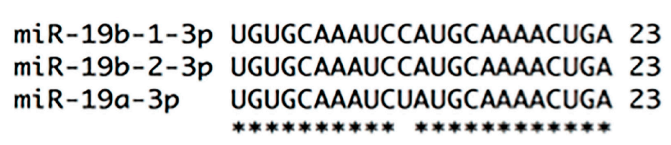

(b)

miR-23b-3p AUCACAUUGCCAGGGAUUACC- 21 miR-23c-3p AUCACAUUGCCAGUGAUUACCC 22 miR-23a-3p AUCACAUUGCCAGGGAUUUCC- 21 ********************

miR-27a-3p UUCACAGUGGCUAAGUUCCGC 21 miR-27b-3p UUCACAGUGGCUAAGUUCUGC 21

(c)

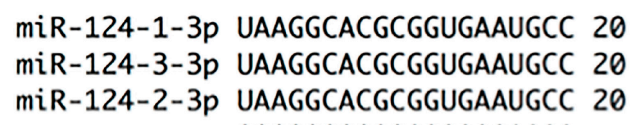

miR-124-2-3p UAAGGCACGCGGUGAAUGCC 20

Figure 4. Alignments of miRNAs families by $3 p$ strand used and nt chain sizes: (a) miR-19 family has $23 \mathrm{nt}$ of length and share $100 \%$ of strand conservation; (b) miR-23 and miR-27 families are in general $21 \mathrm{nt}$ in length except for miR-23c (22 nt). The former has $86.36 \%$ while miR-27 has $95.23 \%$ strand conservation; (c) miR-124 family shares 100\% strand conservation and its members are $20 \mathrm{nt}$ in size. * at the bottom of the alignment indicates nt homology between family members. 


\section{Anti-Oncogenic miR-23 Family Participates in Cervical Cancer}

miR-23 family is composed of miR-23a, miR-23b and miR-23c, the former is in chromosome 19, the middle in chromosome 9 and the last one in chromosome $X$ [20]. The 3p strand is recognized as the guide strand and has less mature sequence difference than $5 p$ strand. The $3 p$ strands have 3 different $n t$ between family members (Figure 4), while the $5 p$ strands have five dissimilar nt and it is present in only two members (Figure 2). miR-23b, a member of this family, is involved in cervical carcinogenesis with a remarkable down-regulation during Steps 2 to 4 of the cervical multistep model of carcinogenesis that we recently proposed [17]. The promoter of miR-23b is methylated in cervical cancer [60] and has a consensus p53-binding site, therefore p53 diminish by the presence of HR-HPV16-E6 oncoprotein induces a down-regulation of miR-23b and an increased expression of uPA via $3^{\prime}$ UTR mRNA binding [61]. This protein is a serine protease that degrades extracellular matrix regulated through Notch signaling, interestingly these two proteins are overexpressed in cervical cancer $[17,18]$. The $3 p$ arm of the three members $(a, b$ and $c)$ of miR-23 family potentially regulate uPA mRNA (microrna.org, MIRDB and Target Scan).

\section{Oncogenic miR-25 Family Participates in Cervical Cancer}

miR-25 family is formed by miR-25, miR-92a-1, miR-92a-2, and miR-92b. The 3p strand of members of this family differs in mature sequence by $6 \mathrm{nt}$. miR-92a-1-3p and miR-92a-2-3p are equal while miR-92a-3p differs in 3 nt with miR-92b-3p (Figure 3). The $5 p$ strand does not have a conserved seed sequence between the family members (Figure 2). However, this observation does not imply that these mature miRNAs do not regulate mRNAs individually. It has been addressed that the members of a same family regulate similar mRNA targets, however, differences in one nucleotide could change mRNA targets specificity and it can be observed that in some families the mature sequence varies in more than $4 \mathrm{nt}$. miR-25-3p and miR-92a are up-regulated in cervical cancer progression [62]. miR-25-3p overexpression suppresses tumor growth in mice and diminishes Semaphorin 4C (Sema 4c) via 3'UTR, Snail, and Vimentin while E-Cadherin increases suppressing epithelial-mesenchymal transition in cisplatin-resistant cells [63]. miR-92 has been shown to be increased in cervical cancer versus normal tissue [34,55,62], and its overexpression in $\mathrm{SiHa}$ and C-33A cells increases proliferation and migration while inhibition induces apoptosis as well as diminishes tumor growth [64]. miR-92a overexpression augments proliferation, G1-S transition and invasion by F-box and WD repeat domain-containing 7 (FBXW7) through 3'UTR [65].

\section{Oncogenic miR-27 Family Participates in Cervical Cancer}

miR-27 family is composed of miR-27a and miR-27b. miR-27a is an intergenic miRNA localized in chromosome 19 while miR-27b is an intronic miRNA located within the fourteenth intron of the human C9orf3 host gene in chromosome 9 [20]. The mature 3p arms of miR-27a and miR-27b differ in one nucleotide and share target mRNAs [66] (Figure 4), while the 5p arms have $5 \mathrm{nt}$ of difference between them (Figure 2). Additionally, miR-27a and miR-27b have opposite expression patterns in the development of cervical carcinoma as the changes are recorded from Step 2 to Step $4[17,67]$. miR-27a binds to $3^{\prime}$ UTR of beta-1,4-Galactosyltransferase III (B4GALT3) increasing protein synthesis. B4GALT3 is responsible for poly- $N$-acetyl lactosamine and is implicated in keratin sulfate/keratin metabolism and transport to Golgi and subsequent modification inducing migration and invasion, probably by increasing $\beta 1$-integrin stability [68]. Two independent works [52,69] have shown an opposite expression for miR-27b compared to the report reviewed in Granados-López et al. [17]. Augmented expression of miR-27b elicits proliferation, G1-S transition, migration and invasion by reducing Peroxisome Proliferator Activated Receptor Gamma (PPAR- $\gamma$ ) and Cadherin 11 (CDH11) protein production via $3^{\prime} \mathrm{UTR}$. PPAR- $\gamma$ is a member of the nuclear receptor family of ligand-activated transcription factors that heterodimerize with the retinoic $X$ receptor (RXR) to regulate gene expression while CDH11 is a calcium-dependent cell adhesion protein that preferentially interacts with itself in 
a homophilic manner in connected cells [52,69]. miR-27a and miR-27b could share several targets, however, their expression patterns differ in cervical cancer; consequently, target genes may be differentially regulated which indicates their relevance in cervical carcinogenesis.

\section{Anti-Oncogenic miR-29 Family Participates in Cervical Cancer}

Another family of miRNAs that shows important changes during Steps 1 to 4 of carcinogenesis is miR-29 family that is formed by miR-29a, $-b$ and $-c[17,70]$. miR-29a has been shown reduced in serum of cervical cancer patients [71]. Interestingly, miR-29s have different subcellular localization while miR-29a and miR-29c are primary expressed in the cytoplasm, miR-29b is expressed in the nucleus [72]. The strand $5 p$ has 14 dissimilar nt implying a great target plethora and differential mechanism of regulation. miR-29a-5p present seven different nt with miR-29b-1-5p, miR-29b-2-5p and miR-29c-5p, additionally, miR-29b-1-5p and miR-29b-2-5p have four different nt (Figure 2). miR-29 members have different effects on cell cycle indicating target specificity [73]. Target specificity could be explained by five dissimilar $n t$ in the guide $3 p$ strand in addition to strand longitude while miR-29-b has $23 \mathrm{nt}$ miR-29a and miR-29c have 22 nt (Figure 3). The proteins YY-1 and Cyclin Dependent Kinase 6 (CDK6) and Heat-shock protein 47 (HSP47) are regulated in Steps 1 and 4, respectively, arguing a fine-tuning regulation of miR-29a and -b in cervical cancer progress [17,74]. YY1 is a ubiquitously distributed transcription factor involved in repressing and activating a diverse number of promoters. CDK6 is a catalytic subunit of the protein kinase complex that is important for cell cycle G1 phase progression and G1/S transition. HSP47 is localized in the endoplasmic reticulum and plays a role in collagen biosynthesis as a collagen-specific molecular chaperone. Expressions of these genes are up-regulated in cervical cancers promoting migration and invasion. Given the similarity among miR-29a, -b and -c (Figure 3), and the prediction of pictar, the 3p arms could regulate YY-1, CDK6, and HSP47.

\section{Anti-Oncogenic miR-34 Family Participates in Cervical Cancer}

One of the best markers of cancer development is the alteration of p53 expression that conduces to cancer progression by the misregulation of its effectors like miR-34 family. miR-34a forced expression inhibits High Mobility Group Box 1 (HMGB1), NLR Family CARD Domain Containing 5 (NLRC5), Lactate Dehydrogenase A (LDHA), E2F Transcription Factor 3 (E2F3) and increases Retinoic acid-inducible gene-1 (RIG-1) protein expression via 3'UTR. HMGB1 is a nuclear DNA-binding protein that regulates transcription and is involved in organization of DNA. This protein plays a role in several cellular processes, including inflammation, cell differentiation and tumor cell migration. NLRC5 plays a role in cytokine response and antiviral immunity through inhibition of NF-kappa-B activation and negative regulation of type I interferon-signaling pathways. LDHA catalyzes the conversion of L-lactate and Nicotinamide Adenine Dinucleotide (NAD) to pyruvate and Nicotinamide Adenine Dinucleotide (reduced form) (NADH) in the final step of anaerobic glycolysis generating faster organelle duplication. E2F3 is a transcriptional factor that recognizes a specific sequence motif in DNA and interacts directly with the retinoblastoma protein (pRB) to regulate the expression of genes involved in cell cycle. RIG-1 is a putative RNA helicase that is implicated in a number of cellular processes involving RNA binding and alteration of RNA secondary structure and it is involved in viral double-stranded RNA recognition and the regulation of immune response. HMGB1, NLRC5, LDHA, and E2F3 increase metabolism, proliferation, migration and invasion while RIG-1 increases apoptosis, delays cell cycle transition and inhibits Epithelial-mesenchymal transition (EMT) [75-79].

The guide strand of miR-34 family members has five different nt (Figure 1), while the passenger strand has 10 dissimilar nt (Figure 3), therefore it could be argued a differential cellular effect in response to the targets regulated by each member. Interestingly, the $5 p$ strand of miR-34b is classified as * strand; nevertheless, the reads achieved in 21 experiments from both strands of this miRNA vary in 19 reads [20].

In contrast, the effect of $5 p$ and $3 p$ arms of miR-34c seems to be complementary. While $5 p$ arm of miR-34c exclusively inhibited cell proliferation, the $3 p$ arm inhibited proliferation, migration, 
invasion, and induced apoptosis [6]. During DNA damage, p53 expression induces cell cycle G1 phase progression delay, and if damage could not be repaired at this point, then the apoptosis program is triggered [80,81]. It could be possible that miR-34c-5p expression affects cell cycle G1 phase [82-86] and that miR-34c-3p expression induces apoptosis. Conversely, once pri-miR-34a and pri-miR-34b/c transcription is finished it is not known how one arm is selected against the other. Previously it was shown that p53 regulates the biogenesis of miRNAs through Drosha interaction, promoting the expression of miR-15a/16b, miR-103/107, miR-143/145, miR-203 and miR-206 [87]. Currently, it is not known whether $\mathrm{p} 53$ regulates miR-34 family arm selection or what other proteins participate in this process, as it has been shown that miRNA mature expression is tissue specific [11].

\section{Anti-Oncogenic miR-99 Family Participates in Cervical Cancer}

miR-99 family that is composed of miR-99a, miR-99b and miR-100 is intriguingly important because has one of the most ancient miRNAs, miR-100. This miRNA arises from miR-10 family [3]. The expression pattern and validated targets of the members of miR-99 family vary in cervical cancer [17]. miR-99a inhibits protein synthesis of TRIB2 via 3'UTR [88]. miR-100 has shown a gradual expression reduction from Step 1 to 4 of carcinogenesis. Additionally, its expression inversely correlated with the expression of PLK1, a key mitotic checkpoint regulatory protein that is usually highly expressed in Step 4 [89]. Interestingly, PLK1 is regulated at protein but not at mRNA level by miR-100 [90]. Other important targets of miR-100 are phosphatase (CTD (carboxy-terminal domain), RNA polymerase II, polypeptide A small phosphatase-like (CTDSPL), enzyme N-Myristoyltransferase 1 (NMT1), Transmembrane Protein 30A (TMEM30A), and chromatin remodeler SWI/SNF Related, Matrix Associated, and Actin Dependent Regulator of Chromatin, Subfamily A, Member 5 (SMARCA5). The three members of miR-99 family show relevance in cervical carcinoma since it has been shown a down-regulation of mRNA and protein of Homeobox A1 (HOXA1) and mTOR via $3^{\prime} \mathrm{UTR}$ in HaCaT cells. Interestingly, down-regulation of the targets of this family hinders proliferation and migration [91], adding importance of loss of function of miR-99 family in cervical carcinogenesis progression. The targets of miR-100, CTDSPL, TMEM30A and SMARCA5 could be potentially regulated by miR-99a and miR-99b as well (Target Scan, microrna.org, MIRDB and pictar). The $5 p$ strands of the members of miR-99 family have four dissimilar nt (Figure 2), while the $3 p$ strands have seven different nt (Figure 3). Seed sequence of the 3p strand has one different nt between miR-99a/b and miR-100 probably adding different target specificity.

\section{Anti-Oncogenic miR-124 Family Participates in Cervical Cancer}

miR-124 family is formed by miR-124-1, miR-124-2 and miR-124-3. First and second miRNAs are localized in chromosome 8 and the third one in chromosome 20. miR-124-1 is transcribed from the negative DNA strand while miR-124-2 and miR-124-3 are transcribed from the positive strand [20]. Recently it has been shown that miR-124 is down-regulated by DNA methylation in cervical cancer progression showing a higher DNA methylation in Step 3 of cancer progression and cervical cancer than in High-Risk Human Papillomavirus (HR-HPV)-positive tissues [92-94] causing Insulin Like Growth Factor Binding Protein 7 (IGFBP7) increase at the mRNA and protein level [92]. IGFBP7 has been implicated in cervical cancer, and it may influence the persistence of HR-HPV infection $[95,96]$. Restoring miR-124 expression, Angiomotin Like 1 (AmotL1) and Astrocyte-Elevated Gene-1 (AEG-1) are down-regulated via $3^{\prime} \mathrm{UTR}$. AmotL1, a peripheral membrane protein that is a component of tight junctions, controls paracellular permeability and maintains cell polarity, while AEG-1 activates the nuclear factor $\mathrm{\kappa}-\mathrm{B}$ (NF-k-B) transcription factor and participates in cytoskeleton remodeling regulation of actin by Rho GTPases. Moreover, miR-124 overexpression inhibits proliferation, migration and invasion [97,98] implying that miR-124 methylation provides advantages for carcinogenesis [92-94]. Given the similarity of $5 p$ and $3 p$ strands it could be possible that both strands are selected equally (Figures 2 and 4), however, the 3p strand is selected preferentially [20]. 


\section{Anti-Oncogenic miR-125 Family Participates in Cervical Cancer}

Family miR-125 is formed by miR-125a, miR-125b-1 and miR-125b-2 localized in chromosomes 19 , 11 and 21, respectively. Interestingly, PI3K/AKT signaling-pathway controls cell growth, cell division and apoptosis, and it is regulated positively and negatively by miR-125 family members. In silico analysis predicts that AKT1 and PIK3CD have miRNA binding sites in coding sequence (CDS) and in $5^{\prime}$ UTR region for miR-125b-3p* and for miR-125a-3p* (RNA22-HSA). PIK3CD has additional sites for miR-125a-5p and miR-125b-5p (Target Scan). mRNA targets and function for some members of this family have been evaluated. By one side miR-125b inhibits PI3K/AKT pathway through down-regulation of mRNA and protein PIK3CD via $3^{\prime} \mathrm{UTR}$ binding conducing to protein kinase A (AKT) and mTOR phosphorylation shrink inducing tumor volume growth inhibition [99]. By the other side miR-125b inhibits BAK1 protein synthesis via mRNA $3^{\prime}$ UTR binding inhibiting apoptosis and inducing tumor growth volume [100]. miR-125b regulates numerous genes such as oncogenes and tumor suppressors; therefore, the number of genes regulated by this miRNA should determine the effect. Intriguingly, miR-125a-5p shows an increased expression while miR-125b-5p records a decrease from Step 2 to Step 4 of carcinogenesis [17]. The described expression of miR-125a is contrary $[101,102]$ to previously reported [17] while miR-125b continuously has shown similar expression [103]. Expression of miR-125a decreases Signal Transducer and Activator of Transcription 3 (STAT3) and ABL Proto-Oncogene 2, Non-Receptor Tyrosine Kinase (ABL2) protein expression via $3^{\prime}$ UTR. STAT3 is a protein that is phosphorylated by the receptor-associated kinases in response to cytokines and growth factors acting as transcription activators in nucleus. ABL2 is non-receptor tyrosine protein kinase and it plays a role in cytoskeletal rearrangements through its C-terminal of F-actin and microtubule-binding sequences. STAT3 and ABL2 augment proliferation, G2/M cell cycle transition, migration, invasion, and tumor growth in cervical cancer [101,102]. 5p strands of these family members have three different nt between them while the $3 p$ strands have seven different $n t$. An additional difference between $5 p$ strands is that miR-125a-5p has 24 instead of $22 \mathrm{nt}$ that shares with miR-125b-5p 1 and 2 (Figures 2 and 3).

\section{7. miR-133 Family Participates in Cervical Cancer}

miR-133 family is formed by miR-133a and -b (Figures 2 and 3), as it can be seen the $5 p$ stand is missing for miR-133b [20] (Figure 2). The strand selection, pri-miRNA, pre-miRNA and chromosomal localization suggest unique type of regulation for the members of this family. $5 p$ and $3 p$ strands share $100 \%$ of homology (Figures 2 and 3), therefore, both strands could be selected by RISC, although $3 p$ strand is usually selected instead. The fact that $5 p$ strand was not identified or annotated for miR-133b [20] probably be the result of a molecular evolution for cell survival.

In cervical cancer, a miR-133a decrease was shown [104], while for miR-133b contrary expression and function was reported. A gradual increase was achieved from Step 2 to Step 4 of carcinogenesis [27,105] although another study reported a reduction in Step 4 [106]. miR-133a diminish correlate with lymph node metastasis, histological grade and International Federation of Gynecology and Obstetrics (FIGO) state whilst its forced expression prompts apoptosis and hinders proliferation, colony formation, migration, invasion and tumorigenesis in vivo through EGFR $3^{\prime} U T R$ mRNA binding restraining AKT-ERK1/2 pathway signaling [104]. On the other hand, miR-133b up-regulation is accompanied by the down-regulation of mammalian sterile 20-like kinase 2 (MST2), cell division control protein 42 homolog (CDC42) and Ras homolog gene family member A (RHOA) at mRNA and protein level. Decreased expression of its targets augments AKT and MAPKs (ERK1 and ERK2) phosphorylation inducing cell proliferation and colony formation in cervical cell lines [105]. Additionally, miR-133b binds to 3'UTR and regulates negatively the expression of Nucleoporin 214 (Nup214). Nup214 is a member of nuclear pore complex forming a gateway that regulates the flow of macromolecules between the nucleus and the cytoplasm. The protein encoded by this gene is localized to the cytoplasmic face of the nuclear pore complex where it is required for proper cell cycle progression, nucleocytoplasmic transport and participates in spindle assembly kinetochore 
organization and chromosome assembly functioning as oncogene [106]. Interestingly, despite strand $3 p$ similitude the effects between miR-133a and $-b$ are opposed. This is a clear example of the existence of a very specific strand selection mechanism for gene silencing. miRNA strand selection mechanism elucidation is a major subject of study that will widen the understanding of miRNA function regulation.

\section{Oncogenic miR-146 Family Participates in Cervical Cancer}

miR-146 family is formed by miR-146a and miR-146b that are encoded in chromosomes 5 and 10, respectively [20]. The two members of this family show an increased expression in cervical cancer. Importantly, miR-146a records an increase from Step 2 to 4 of carcinogenesis [17]. The overexpression of miR-146a in cervical cancer does not correlate with its function because its forced expression inhibits proliferation, migration and invasion in cell lines [107]. Strands 5p of miR-146 a and b have 2 nt of difference whilst $3 p$ strands have nine dissimilar nt (Figures 2 and 3). It is worth noting that the $3 p$ strands could present differential target regulation.

\section{Oncogenic miR-181 Family Participates in Cervical Cancer}

miR-181 family is formed as follows: miR-181a- 1 and miR-181b- 1 is clustered in chromosome 1 and miR-181a-2 and miR-181b-2 cluster located in chromosome 9. The miR-181c and miR-181d cluster is located in chromosome 19 and the members differ on their sequence in $2 \mathrm{nt}$ for strands $5 \mathrm{p}$ and 11 nucleotides for strands $3 p$ [108]. It should be noted that the $5 p$ strand for miR-181a and $-b$ share identical sequence in contrast to $3 p$ strands with 3 and 2 nt different, respectively (Figures 1 and 3 ). It has been reported recently that miR-181a confers radiochemo-resistance by diminishing mRNA and proteins of PKC via $3^{\prime}$ UTR binding, therefore decreasing caspase $3 / 7$ activity and hindering apoptosis $[109,110]$. miR-181b down-regulates adenylyl cyclase (AC), restricting cAMP production and promoting cell proliferation and apoptosis diminution [111]. cAMP production is conducive to PKA activation, which induces transcription of smac/Diablo by CREB, which leads to caspase activation [112]. In contrast miR-181a inhibition halts proliferation, cell cycle by p21 and p27 expression as well as apoptosis induction through Bax increase and Bcl-2 decrease. Moreover, PTEN expression is augmented and AKT and FOXO1 phosphorylation diminished [113]. These pathways seem to be regulated by the $5 p$ strand of the members of miR-181 family, in agreement with their similarity and in silico predictions (microrna.org, MIRDB, and Target Scan).

\section{0. miR-196 Family Participates in Cervical Cancer}

miR-196 family is formed by miR-196a-1, miR-196a-2 and miR-196b that are localized in chromosomes 17, 12 and 7, generated from negative, positive and negative DNA strands, respectively. Interestingly, the 3p strand is not annotated for miR-196a [20] (Figure 3). miR-196a is overexpressed in serum [114], Cervical Intraepithelial Neoplasia (CIN) 2-3 and cervical cancer tissues inducing proliferation and migration, diminishing mRNA and protein of Netrin 4 (NTN4) via $3^{\prime} \mathrm{UTR}$. This protein is a member of Netrin family that promotes neurite growth and cell branching [115]. Furthermore, it has been demonstrated that HOXB8, FOXO1 and p27 kip1 are direct targets of miR-196a increasing Cyclin D1 and diminishing p21 mRNAs [116,117]. However, it should be noted that Liu et al., 2015 [116] and Hou et al., 2014 [117] presented different miR-196a expression. The former reported a diminished expression of miR-196a analyzed by microarrays and Reverse Transcription Polymerase Chain Reaction (RT-PCR) comparing normal tissues with HPV-positive cervix and cervical carcinoma tissues [116]. The last one, recordered an increase of miR-196a expression, by RT-PCR, comparing cervical cancer tissues and cell lines with normal cervical tissues. Additionally, a correlation with advanced tumor stage, poor overall and recurrence-free survival and up-regulation of miR-196a in cervical cancer patients was shown [117]. Both works used the same gene to normalize expression but they used different RNA extraction methods and quantities. An additional difference lays in the type of tissues used in the assays, while Hou et al., 2014 [117] used adjacent normal tissues, Liu et al., 2015 [116] used tissues from different patients. This issue has been common for several works as has 
been reported before [17]. Interestingly, miR-196b is reduced in cervical cancer compared to normal tissue showing an opposed expression to miR-196a [17]. The 5p strands of miR-196a-1, miR-196a-2 and miR-196b differ in $1 \mathrm{nt}$ (Figure 2), whereas 3p strand of miR-196a-1 is not annotated, and the strands of miR-196a-2-3p and miR-196b-3p are totally different (Figure 3).

\section{1. miR-200 Family Participates in Cervical Cancer}

miR-200 family is formed by miR-200a, miR-200b and miR-200c. The members of this family are localized in chromosome 1 expressing miR-200a and miR-200b while chromosome 12 contains miR-200c [20,118]. miR-200a* shows an increase from Step 2 and miR-200c incorporates overexpression in Step 3 participating in cervical carcinogenesis [17]. miR-200a has been reported overexpressed in serum [71] whereas miR-200b has a controversial reported expression, while Cheng et al. [119] and Cheng et al. reported [120] a down-regulation, Zeng et al. reported an up-regulation [121]. miR-200b mimic reduces migration and it seems that its overexpression inhibits EMT because $E$-cadherin is augmented and vimentin a matrix metalloproteinase-9 is decreased [119] by targeting RhoE directly which binds Guanosine-5'-triphosphate (GTP) but has no GTPase activity, and appears to act as a negative regulator of cytoskeletal organization leading to loss of adhesion, favoring migration and invasion [120]. On the other hand, miR-200b inhibition inhibits cell migration, invasion and tumor growth by targeting Forkhead Box G1 (FoxG1) a transcriptional repressor [121]. It should be noted that miRNAs have hundreds of mRNAs targets that could be regulated at the same time and that probably the sum of all genes regulated give a particular effect affecting cell signaling pathways and cellular processes [18]. Therefore, the dissimilar sequence for every family member should be taken into account. The $5 p$ strands differ in $10 \mathrm{nt}$ in their sequence while, $3 \mathrm{p}$ strands differ in $6 \mathrm{nt}$. miR-200a-5p differs in $5 \mathrm{nt}$ with miR-200b-5p and $7 \mathrm{nt}$ with miR-200c-5p. miR-200a-3p differs in $5 \mathrm{nt}$ with miR-200b-3p and 6 nt with miR-200c-3p. miR-200c-3p has 23 nt instead of 22 (Figures 2 and 3). In general, for these members, they do not have conserved seed sequence, in both strands it varies in $1 \mathrm{nt}$. In addition to these features, we should consider that $\geq 1 \mathrm{nt}$ are added in the biogenesis produced by Dicer, and by the activity of other proteins and enzymes [12,15,122,123].

\section{Conclusions}

miRNA expression has been linked to cancer progression [17] by the regulation of several cellular pathways [18]. Notably, miRNA expression has plentiful levels of regulation, including transcription, biogenesis, stability and addition of several modifications increasing variability of targets and regulation of cellular processes $[7,9,15,122,124]$. Nevertheless, the strand selection, pre-miRNA and genomic context of miRNA families have not been considered in cancer therapy, diagnosis or prognosis. In this work, we point out the importance of strand preference, conservation and expression of miRNAs families associated with cervical cancer. In general, we observed a constant expression of miRNA guide strand from some members of miRNA families, however for miR-10a, miR-15a, miR-16, and miR-200a expression of both guide and star strands was noticed. Importantly, it is unknown the miRNA star strand expression of the rest of the members of the 20 miRNAs families associated with cervical cancer. Percent increase of conservation could have a preserved program of gene regulation leading to guide and star strand expression. miRNA families associated with cervical cancer present a guide strand conservation that varies from $100 \%$ to $54.45 \%$ while a less star strand conservation for all family members is noticed. Interestingly, miR-9, miR-124 and miR-133 families present $100 \%$ of conservation between strands suggesting $50 \%$ probability of strand selection, however, for an unclear mechanism it seems that one strand is preferentially selected for degradation by a complex of proteins [125] or by absence of mRNA targets that as well induces miRNA degradation that could contribute to strand survival [126].

$5 p$ strand is preferred for miR-9 family while miR-124 and miR-133 families used 3p strand showing $100 \%$ conservation. $5 p$ strand of miR-7 family is chosen preferentially and has $100 \%$ conservation. miR-10, miR-27 and miR-196 families share more than 95\% conservation. miR-146 
and miR-181 families have $90 \%$; miR-23 and miR-125 have $86.36 \%$; and miR-1, miR-19 and miR-99 have $81.81 \%$ conservation. miR-17, miR-29 and miR-34 families have $~ 77 \%$ whilst miR-25 and miR-200 families have $72.72 \%$, and finally the less conserved of all the families associated with cervical cancer, miR-15 family has $54.45 \%$ of conservation.

In addition to the percentage of conservation, these families present different sizes in nt chain length. In general, mature 5p strands are larger, showing in this review that two miRNAs are $24 \mathrm{nt}$, 24 miRNAs $23 \mathrm{nt}, 35$ miRNAs $22 \mathrm{nt}$ and three miRNAs $21 \mathrm{nt}$ long. Regarding 3p strand, it was observed that seven miRNAs are $23 \mathrm{nt}, 50$ miRNAs $22 \mathrm{nt}$, six miRNAs $21 \mathrm{nt}$ and four miRNAs $20 \mathrm{nt}$ long. Length size differences could change mRNA target, binding of proteins and factors, and conformational changes in miRISC triggering different mechanisms of regulation. Drosha and Dicer determine the $5 p$ and $3 p$ strands sequence, respectively. It has been reported that $3^{\prime}$ end of $5 p$ strands and $5^{\prime}$ of $3 p$ strands of miRNAs are frequently modified by Dicer, and other proteins [14], however we observed modifications in the $5^{\prime}$ of $5 p$ strands of miR-9, miR-34b, miR-34c, miR-181a-1, miR-181a-2, miR-181b-1, miR-181b-2, miR-181c, miR-181d, miR-200c and miR-106b making the guide strand in some cases bigger and in others smaller. Changes in $5^{\prime}$ and $3^{\prime}$ ends of $5 \mathrm{p}$ and $3 \mathrm{p}$ strands must be regulated in fine-tuning mode in response to several stimuli raising numerous questions: What proteins, RNAs or molecules regulate these mechanisms? What modifications in proteins that participate in miRNA biogenesis regulate them? What RNA modifications, such as phosphorylation, methylation, base modifications, etc., regulate these mechanisms?

The analysis of the 20 miRNAs families associated with cervical cancer preferentially selects $673 p$ and $655 p$ strands. Several families miss miRNA strand conservation and use, such as miR-1 family (miR-1-2-5p and miR-206-5p), miR-23 family (miR-23c-5p), miR-133 (miR-133b-5p), miR-7 family (miR-7-3-3p), and miR-196 (miR-196-1-3p). Four and two 5p and $3 p$ strands, respectively, are absent, suggesting $3 p$ strand preference for the 20 miRNAs families associated with cervical cancer. Remarkable $3 p$ and $5 p$ strands are equally conserved through miRNA evolution and used by miRNA families. In this context, from 11 miRNAs families that use $5 p$ strand, six and three are anti-oncogenic and oncogenic, respectively. miR-7, miR-9, miR-15, miR-34, miR-99, and miR-125 families participate in MAPK, PI3K-AKT, Jak/STAT3, and mTOR cell-signaling pathways' regulation as well as in apoptosis, cell cycle, autophagy, and EMT potentiating cervical carcinoma development. In contrast, miR-17, miR-146, and miR-181 families are involved in DNA repair systems, telomerase activity increase, autophagy, endocytic sorting and traffic of proteins, and Ras-MAPK modulation potentiating cervical carcinogenesis. These cell signals among other proteins contribute to cell process homeostasis that in cervical cancer are misregulated by the strand expression of miRNA families.

In the case of the 9 miRNAs families that select $3 p$ strand, each four are anti-oncogenic and oncogenic. miR-1, miR-23, miR-29, and miR-124 are implicated in glucose metabolism, Notch signaling, cell adhesion, cytoskeleton remodeling, and cell cycle. miR-19, miR-25, miR-27, and miR-200 are associated with EMT, ubiquin ligase complexes, and Golgi transport. It is important to note that miR-10, miR-133 and miR-196 families are not possible to be marked with a particular function because the three families have two mature miRNA sequences with an opposite function (Table 1). However, in general, 10 mature miRNAs families with anti-oncogenic functions are insufficient to avoid tumorigenesis triggered by seven oncogenic mature miRNA families impacting in proliferation, anchorage independent growth, apoptosis, migration, invasion, autophagy, and Warburg effect taken into account the information available until now. Another central point that should be taken in consideration is that miRNA mature strand expression does not always correlate with its function (Table 1). Nevertheless, miRNA signature could be used for diagnosis and prognosis [17], however for therapy, function must be evaluated and the mechanism elucidated before its use. Expression diminish of miR-29 [74] and miR-218 [127] among others is well documented through CIN 1, 2, 3 and cervical cancer [17]. Based on miRNA expression, it is possible to know the stage of cancer progression, making them ideal molecular markers for diagnosis. Up-regulation of miR-155 [21] and miR-196a [114] and down-regulation of miR-26a [128], miR-125a [101], and miR-126 [129] are associated with poor 
survival of patients with cervical cancer predicting relapse and survival of patients. Regarding miRNA therapy, it should be taken into account that miRNA overexpression or inhibition could present RNAi off-target [130]. Additionally, it was reported that miR-34a overexpression is not functional if it is not phosphorylated [131]. Known and unknown mechanisms have limited miRNA-based therapy, therefore extensive mechanistic studies are needed to understand the complex miRNA biogenesis, availability of RISC complex and miRNAs modifications that are necessary to achieve therapy efficacy. Furthermore, some proteins and RNAs in miRNA strand selection are still unknown, important for possible miRNA based therapy. In contrast, there are numerous miRNAs, both the $5 p$ and $3 p$ strands, with unknown expression and function that could be important in cervical development, which were not included in this work.

In should be noted that pre-miRNA and genomic context are different for all miRNAs families [20]. It seems that the passenger strand has more variability than guide strand generating two hypotheses: (1) it could be argued that passenger strand has more difference in nucleotides between family members than guide strand because it is usually degraded, therefore the selection machinery is not specific; (2) it could be said that sequence difference in passenger and guide strands between family members obeys specific and fine-tuned biogenesis selection to redirect the regulation of diverse specific set of target mRNAs generated by sequence heterogeneity of the passenger strand. miRNA modifications, strand selection and function are a central issue in cervical cancer development. The findings of these issues could contribute to accurate design of miRNA therapy, diagnosis and prognosis approaches.

Acknowledgments: This work was supported by Consejo Nacional de Ciencia y Tecnología (CONACYT) (Grant No. 177620), Fondo Mixto de Fomento a la Investigación Científica y Tecnológica CONACYT-Gobierno del Estado de Zacatecas (FOMIX-ZACATECAS) (Grant No. 203155), and Programa de Mejoramiento del Profesorado (PROMEP) (Grant No. 17192).

Author Contributions: Angelica Judith Granados-López analyzed and organized the literature and wrote the paper; José Luis Ruiz-Carrillo and Luis Steven Servín-González made alignments, table and revised the manuscript; José Luis Martínez-Rodríguez, Claudia Araceli Reyes-Estrada and Rosalinda Gutiérrez-Hernández searched and organized literature; and Jesús Adrián López analyzed the literature, organized the data, and created the original idea.

Conflicts of Interest: The authors declare no conflict of interest.

\section{References}

1. Demuth, J.P.; de Bie, T.; Stajich, J.E.; Cristianini, N.; Hahn, M.W. The evolution of mammalian gene families. PLoS ONE 2006, 1, e85. [CrossRef] [PubMed]

2. Chhabra, R.; Dubey, R.; Saini, N. Cooperative and individualistic functions of the micrornas in the miR-23a 27a 24-2 cluster and its implication in human diseases. Mol. Cancer 2010, 9, 232. [CrossRef] [PubMed]

3. Tehler, D.; Hoyland-Kroghsbo, N.M.; Lund, A.H. The miR-10 microRNA precursor family. RNA Biol. 2011, 8 , 728-734. [CrossRef] [PubMed]

4. Wang, W.X.; Danaher, R.J.; Miller, C.S.; Berger, J.R.; Nubia, V.G.; Wilfred, B.S.; Neltner, J.H.; Norris, C.M.; Nelson, P.T. Expression of miR-15/107 family microRNAs in human tissues and cultured rat brain cells. Genom. Proteom. Bioinform. 2014, 12, 19-30. [CrossRef] [PubMed]

5. Yu, J.; Wang, F.; Yang, G.H.; Wang, F.L.; Ma, Y.N.; Du, Z.W.; Zhang, J.W. Human microRNA clusters: Genomic organization and expression profile in leukemia cell lines. Biochem. Biophys. Res. Commun. 2006, 349, 59-68. [CrossRef] [PubMed]

6. Lopez, J.A.; Alvarez-Salas, L.M. Differential effects of miR-34c-3p and miR-34c-5p on SiHa cells proliferation apoptosis, migration and invasion. Biochem. Biophys. Res. Commun. 2011, 409, 513-519. [CrossRef] [PubMed]

7. He, L.; He, X.; Lim, L.P.; de Stanchina, E.; Xuan, Z.; Liang, Y.; Xue, W.; Zender, L.; Magnus, J.; Ridzon, D.; et al. A microRNA component of the p53 tumour suppressor network. Nature 2007, 447, 1130-1134. [CrossRef] [PubMed]

8. Kong, Y.W.; Cannell, I.G.; de Moor, C.H.; Hill, K.; Garside, P.G.; Hamilton, T.L.; Meijer, H.A.; Dobbyn, H.C.; Stoneley, M.; Spriggs, K.A.; et al. The mechanism of micro-RNA-mediated translation repression is determined by the promoter of the target gene. Proc. Natl. Acad. Sci. USA 2008, 105, 8866-8871. [CrossRef] [PubMed] 
9. Das, A.K.; Carmichael, G.G. Adar editing wobbles the microRNA world. ACS Chem. Biol. 2007, 2, $217-220$. [CrossRef] [PubMed]

10. Katoh, T.; Sakaguchi, Y.; Miyauchi, K.; Suzuki, T.; Kashiwabara, S.; Baba, T.; Suzuki, T. Selective stabilization of mammalian microRNAs by $3^{\prime}$ adenylation mediated by the cytoplasmic poly(A) polymerase GLD-2. Genes Dev. 2009, 23, 433-438. [CrossRef] [PubMed]

11. Landgraf, P.; Rusu, M.; Sheridan, R.; Sewer, A.; Iovino, N.; Aravin, A.; Pfeffer, S.; Rice, A.; Kamphorst, A.O.; Landthaler, M.; et al. A mammalian microRNA expression atlas based on small RNA library sequencing. Cell 2007, 129, 1401-1414. [CrossRef] [PubMed]

12. Starega-Roslan, J.; Koscianska, E.; Kozlowski, P.; Krzyzosiak, W.J. The role of the precursor structure in the biogenesis of microRNA. Cell. Mol. Life Sci. CMLS 2011, 68, 2859-2871. [CrossRef] [PubMed]

13. Noland, C.L.; Doudna, J.A. Multiple sensors ensure guide strand selection in human RNAi pathways. RNA 2013, 19, 639-648. [CrossRef] [PubMed]

14. Meijer, H.A.; Smith, E.M.; Bushell, M. Regulation of miRNA strand selection: Follow the leader? Biochem. Soc. Trans. 2014, 42, 1135-1140. [CrossRef] [PubMed]

15. Davis-Dusenbery, B.N.; Hata, A. Mechanisms of control of microRNA biogenesis. J. Biochem. 2010, 148, 381-392. [PubMed]

16. Suzuki, H.I.; Miyazono, K. Emerging complexity of microRNA generation cascades. J. Biochem. 2011, 149, 15-25. [CrossRef] [PubMed]

17. Granados Lopez, A.J.; Lopez, J.A. Multistep model of cervical cancer: Participation of miRNAs and coding genes. Int J. Mol. Sci. 2014, 15, 15700-15733. [CrossRef] [PubMed]

18. Servin-Gonzalez, L.S.; Granados-Lopez, A.J.; Lopez, J.A. Families of microRNAs expressed in clusters regulate cell signaling in cervical cancer. Int. J. Mol. Sci. 2015, 16, 12773-12790. [CrossRef] [PubMed]

19. Sweetman, D.; Goljanek, K.; Rathjen, T.; Oustanina, S.; Braun, T.; Dalmay, T.; Munsterberg, A. Specific requirements of MRFs for the expression of muscle specific microRNAs, miR-1, miR-206 and miR-133. Dev. Biol. 2008, 321, 491-499. [CrossRef] [PubMed]

20. Kozomara, A.; Griffiths-Jones, S. Mirbase: Annotating high confidence microRNAs using deep sequencing data. Nucleic Acids Res. 2014, 42, D68-D73. [CrossRef] [PubMed]

21. Fang, H.; Shuang, D.; Yi, Z.; Sheng, H.; Liu, Y. Up-regulated microRNA-155 expression is associated with poor prognosis in cervical cancer patients. Biomed. Pharmacother. 2016, 83, 64-69. [CrossRef] [PubMed]

22. Liu, S.; Zhang, P.; Chen, Z.; Liu, M.; Li, X.; Tang, H. MicroRNA-7 downregulates XIAP expression to suppress cell growth and promote apoptosis in cervical cancer cells. FEBS Lett. 2013, 587, 2247-2253. [CrossRef] [PubMed]

23. Hao, Z.; Yang, J.; Wang, C.; Li, Y.; Zhang, Y.; Dong, X.; Zhou, L.; Liu, J.; Zhang, Y.; Qian, J. MicroRNA-7 inhibits metastasis and invasion through targeting focal adhesion kinase in cervical cancer. Int. J. Clin. Exp. Med. 2015, 8, 480-487. [PubMed]

24. Rao, Q.; Shen, Q.; Zhou, H.; Peng, Y.; Li, J.; Lin, Z. Aberrant microRNA expression in human cervical carcinomas. Med. Oncol. 2012, 29, 1242-1248. [CrossRef] [PubMed]

25. Witten, D.; Tibshirani, R.; Gu, S.G.; Fire, A.; Lui, W.O. Ultra-high throughput sequencing-based small RNA discovery and discrete statistical biomarker analysis in a collection of cervical tumours and matched controls. BMC Biol. 2010, 8, 58. [CrossRef] [PubMed]

26. Cheung, T.H.; Man, K.N.; Yu, M.Y.; Yim, S.F.; Siu, N.S.; Lo, K.W.; Doran, G.; Wong, R.R.; Wang, V.W.; Smith, D.I.; et al. Dysregulated microRNAs in the pathogenesis and progression of cervical neoplasm. Cell Cycle 2012, 11, 2876-2884. [CrossRef] [PubMed]

27. Lee, J.W.; Choi, C.H.; Choi, J.J.; Park, Y.A.; Kim, S.J.; Hwang, S.Y.; Kim, W.Y.; Kim, T.J.; Lee, J.H.; Kim, B.G.; et al. Altered microRNA expression in cervical carcinomas. Clin. Cancer Res. 2008, 14, 2535-2542. [CrossRef] [PubMed]

28. Liu, W.; Gao, G.; Hu, X.; Wang, Y.; Schwarz, J.K.; Chen, J.J.; Grigsby, P.W.; Wang, X. Activation of miR-9 by human papillomavirus in cervical cancer. Oncotarget 2014, 5, 11620-11630. [CrossRef] [PubMed]

29. Vojtechova, Z.; Sabol, I.; Salakova, M.; Smahelova, J.; Zavadil, J.; Turek, L.; Grega, M.; Klozar, J.; Prochazka, B.; Tachezy, R. Comparison of the miRNA profiles in HPV-positive and HPV-negative tonsillar tumors and a model system of human keratinocyte clones. BMC Cancer 2016, 16, 382. [CrossRef] [PubMed] 
30. Zhang, J.; Jia, J.; Zhao, L.; Li, X.; Xie, Q.; Chen, X.; Wang, J.; Lu, F. Down-regulation of microRNA-9 leads to activation of il-6/Jak/STAT3 pathway through directly targeting IL-6 in Hela cell. Mol. Carcinogen. 2016, 55, 732-742. [CrossRef] [PubMed]

31. Sun, Y.M.; Lin, K.Y.; Chen, Y.Q. Diverse functions of miR-125 family in different cell contexts. J. Hematol. Oncol. 2013, 6, 6. [CrossRef] [PubMed]

32. Pereira, P.M.; Marques, J.P.; Soares, A.R.; Carreto, L.; Santos, M.A. MicroRNA expression variability in human cervical tissues. PLoS ONE 2010, 5, e11780. [CrossRef] [PubMed]

33. Li, J.H.; Xiao, X.; Zhang, Y.N.; Wang, Y.M.; Feng, L.M.; Wu, Y.M.; Zhang, Y.X. MicroRNA miR-886-5p inhibits apoptosis by down-regulating Bax expression in human cervical carcinoma cells. Gynecol. Oncol. 2011, 120, 145-151. [CrossRef] [PubMed]

34. Wilting, S.M.; Snijders, P.J.; Verlaat, W.; Jaspers, A.; van de Wiel, M.A.; van Wieringen, W.N.; Meijer, G.A.; Kenter, G.G.; Yi, Y.; le Sage, C.; et al. Altered microRNA expression associated with chromosomal changes contributes to cervical carcinogenesis. Oncogene 2013, 32, 106-116. [CrossRef] [PubMed]

35. Li, M.Y.; Hu, X.X. Meta-analysis of microRNA expression profiling studies in human cervical cancer. Med. Oncol. 2015, 32, 510. [CrossRef] [PubMed]

36. Long, M.J.; Wu, F.X.; Li, P.; Liu, M.; Li, X.; Tang, H. MicroRNA-10a targets CHL1 and promotes cell growth, migration and invasion in human cervical cancer cells. Cancer Lett. 2012, 324, 186-196. [CrossRef] [PubMed]

37. Zeng, T.; Li, G. MicroRNA10a enhances the metastatic potential of cervical cancer cells by targeting phosphatase and tensin homologue. Mol. Med. Rep. 2014, 10, 1377-1382. [PubMed]

38. Zou, D.; Zhou, Q.; Wang, D.; Guan, L.; Yuan, L.; Li, S. The downregulation of microRNA-10b and its role in cervical cancer. Oncol. Res. 2016, 24, 99-108. [CrossRef] [PubMed]

39. Finnerty, J.R.; Wang, W.X.; Hebert, S.S.; Wilfred, B.R.; Mao, G.; Nelson, P.T. The miR-15/107 group of microRNA genes: Evolutionary biology, cellular functions, and roles in human diseases. J. Mol. Biol. 2010, 402, 491-509. [CrossRef] [PubMed]

40. Zhang, Y.; Zhang, D.; Wang, F.; Xu, D.; Guo, Y.; Cui, W. Serum miRNAs panel (miR-16-2*, miR-195, miR-2861, miR-497) as novel non-invasive biomarkers for detection of cervical cancer. Sci. Rep. 2015, 5, 17942. [CrossRef] [PubMed]

41. Huang, N.; Wu, J.; Qiu, W.; Lyu, Q.; He, J.; Xie, W.; Xu, N.; Zhang, Y. MiR-15a and miR-16 induce autophagy and enhance chemosensitivity of camptothecin. Cancer Biol. Ther. 2015, 16, 941-948. [CrossRef] [PubMed]

42. Druz, A.; Chen, Y.C.; Guha, R.; Betenbaugh, M.; Martin, S.E.; Shiloach, J. Large-scale screening identifies a novel microRNA, miR-15a-3p, which induces apoptosis in human cancer cell lines. RNA Biol. 2013, 10, 287-300. [CrossRef] [PubMed]

43. Zubillaga-Guerrero, M.I.; Alarcon-Romero Ldel, C.; Illades-Aguiar, B.; Flores-Alfaro, E.; Bermudez-Morales, V.H.; Deas, J.; Peralta-Zaragoza, O. MicroRNA miR-16-1 regulates CCNE1 (cyclin E1) gene expression in human cervical cancer cells. Int. J. Clin. Exp. Med. 2015, 8, 15999-16006. [PubMed]

44. Wang, N.; Wei, H.; Yin, D.; Lu, Y.; Zhang, Y.; Zhang, Q.; Ma, X.; Zhang, S. MicroRNA-195 inhibits proliferation of cervical cancer cells by targeting cyclin D1A. Tumour Biol. 2016, 37, 4711-4720. [CrossRef] [PubMed]

45. Du, X.; Lin, L.I.; Zhang, L.; Jiang, J. MicroRNA-195 inhibits the proliferation, migration and invasion of cervical cancer cells via the inhibition of CCND2 and myb expression. Oncol. Lett. 2015, 10, 2639-2643. [CrossRef] [PubMed]

46. Li, Z.; Wang, H.; Wang, Z.; Cai, H. MiR-195 inhibits the proliferation of human cervical cancer cells by directly targeting cyclin d1. Tumour Biol. 2016, 37, 6457-6463. [CrossRef] [PubMed]

47. Zhou, Q.; Han, L.R.; Zhou, Y.X.; Li, Y. MiR-195 suppresses cervical cancer migration and invasion through targeting Smad3. Int. J. Gynecol. Cancer 2016, 26, 817-824. [CrossRef] [PubMed]

48. Shin, C.; Nam, J.W.; Farh, K.K.; Chiang, H.R.; Shkumatava, A.; Bartel, D.P. Expanding the microRNA targeting code: Functional sites with centered pairing. Mol. Cell 2010, 38, 789-802. [CrossRef] [PubMed]

49. Cipolla, G.A. A non-canonical landscape of the microRNA system. Front. Genet. 2014, 5, 337. [CrossRef] [PubMed]

50. Su, W.; Slepenkov, S.V.; Slevin, M.K.; Lyons, S.M.; Ziemniak, M.; Kowalska, J.; Darzynkiewicz, E.; Jemielity, J.; Marzluff, W.F.; Rhoads, R.E. MRNAs containing the histone $3^{\prime}$ stem-loop are degraded primarily by decapping mediated by oligouridylation of the $3^{\prime}$ end. RNA 2013, 19, 1-16. [CrossRef] [PubMed] 
51. Ventura, A.; Young, A.G.; Winslow, M.M.; Lintault, L.; Meissner, A.; Erkeland, S.J.; Newman, J.; Bronson, R.T.; Crowley, D.; Stone, J.R.; et al. Targeted deletion reveals essential and overlapping functions of the miR-17 through 92 family of miRNA clusters. Cell 2008, 132, 875-886. [CrossRef] [PubMed]

52. Liu, F.; Zhang, S.; Zhao, Z.; Mao, X.; Huang, J.; Wu, Z.; Zheng, L.; Wang, Q. MicroRNA-27b up-regulated by human papillomavirus $16 \mathrm{E} 7$ promotes proliferation and suppresses apoptosis by targeting polo-like kinase2 in cervical cancer. Oncotarget 2016, 7, 19666-19679. [CrossRef] [PubMed]

53. Chiantore, M.V.; Mangino, G.; Iuliano, M.; Zangrillo, M.S.; de Lillis, I.; Vaccari, G.; Accardi, R.; Tommasino, M.; Columba Cabezas, S.; Federico, M.; et al. Human papillomavirus E6 and E7 oncoproteins affect the expression of cancer-related microRNAs: Additional evidence in HPV-induced tumorigenesis. J. Cancer Res. Clin. Oncol. 2016, 142, 1751-1763. [CrossRef] [PubMed]

54. Liu, S.; Pan, X.; Yang, Q.; Wen, L.; Jiang, Y.; Zhao, Y.; Li, G. MicroRNA-18a enhances the radiosensitivity of cervical cancer cells by promoting radiation-induced apoptosis. Oncol. Rep. 2015, 33, 2853-2862. [CrossRef] [PubMed]

55. Kang, H.W.; Wang, F.; Wei, Q.; Zhao, Y.F.; Liu, M.; Li, X.; Tang, H. MiR-20a promotes migration and invasion by regulating TNKS2 in human cervical cancer cells. FEBS Lett. 2012, 586, 897-904. [CrossRef] [PubMed]

56. Zhao, S.; Yao, D.; Chen, J.; Ding, N.; Ren, F. MiR-20a promotes cervical cancer proliferation and metastasis in vitro and in vivo. PLoS ONE 2015, 10, e120905. [CrossRef] [PubMed]

57. Zhang, J.; Wang, F.; Xu, J.; Wang, X.; Ye, F.; Xie, X. Micro ribonucleic acid-93 promotes oncogenesis of cervical cancer by targeting RAB11 family interacting protein 1. J. Obstet. Gynaecol. Res. 2016, 42, 1168-1179. [CrossRef] [PubMed]

58. Cheng, Y.; Guo, Y.; Zhang, Y.; You, K.; Li, Z.; Geng, L. MicroRNA-106b is involved in transforming growth factor $\beta 1$-induced cell migration by targeting disabled homolog 2 in cervical carcinoma. J. Exp. Clin. Cancer Res. 2016, 35, 11. [CrossRef]

59. Xu, X.M.; Wang, X.B.; Chen, M.M.; Liu, T.; Li, Y.X.; Jia, W.H.; Liu, M.; Li, X.; Tang, H. MicroRNA-19a and $-19 \mathrm{~b}$ regulate cervical carcinoma cell proliferation and invasion by targeting CUL5. Cancer Lett. 2012, 322, 148-158. [CrossRef] [PubMed]

60. Campos-Viguri, G.E.; Jimenez-Wences, H.; Peralta-Zaragoza, O.; Torres-Altamirano, G.; Soto-Flores, D.G.; Hernandez-Sotelo, D.; Alarcon-Romero Ldel, C.; Jimenez-Lopez, M.A.; Illades-Aguiar, B.; Fernandez-Tilapa, G. $\mathrm{MiR}-23 \mathrm{~b}$ as a potential tumor suppressor and its regulation by DNA methylation in cervical cancer. Infect. Agent Cancer 2015, 10, 42. [CrossRef] [PubMed]

61. Au Yeung, C.L.; Tsang, T.Y.; Yau, P.L.; Kwok, T.T. Human papillomavirus type 16 E6 induces cervical cancer cell migration through the p53/microRNA-23b/urokinase-type plasminogen activator pathway. Oncogene 2011, 30, 2401-2410. [CrossRef] [PubMed]

62. Wang, X.; Wang, H.K.; Li, Y.; Hafner, M.; Banerjee, N.S.; Tang, S.; Briskin, D.; Meyers, C.; Chow, L.T.; Xie, X.; et al. MicroRNAs are biomarkers of oncogenic human papillomavirus infections. Proc. Natl. Acad. Sci. USA 2014, 111, 4262-4267. [CrossRef] [PubMed]

63. Song, J.; Li, Y. MiR-25-3p reverses epithelial-mesenchymal transition via targeting Sema4C in cisplatin-resistance cervical cancer cells. Cancer Sci. 2016, 108, 23-31. [CrossRef] [PubMed]

64. Yu, Y.; Zhang, Y.; Zhang, S. MicroRNA-92 regulates cervical tumorigenesis and its expression is upregulated by human papillomavirus-16 E6 in cervical cancer cells. Oncol. Lett. 2013, 6, 468-474. [PubMed]

65. Zhou, C.; Shen, L.; Mao, L.; Wang, B.; Li, Y.; Yu, H. MiR-92a is upregulated in cervical cancer and promotes cell proliferation and invasion by targeting FBXW7. Biochem. Biophys. Res. Commun. 2015, 458, 63-69. [CrossRef] [PubMed]

66. Zhang, M.; Wu, J.F.; Chen, W.J.; Tang, S.L.; Mo, Z.C.; Tang, Y.Y.; Li, Y.; Wang, J.L.; Liu, X.Y.; Peng, J.; et al. MicroRNA-27a/b regulates cellular cholesterol efflux, influx and esterification/hydrolysis in THP-1 macrophages. Atherosclerosis 2014, 234, 54-64. [CrossRef] [PubMed]

67. Gocze, K.; Gombos, K.; Kovacs, K.; Juhasz, K.; Gocze, P.; Kiss, I. MicroRNA expressions in HPV-induced cervical dysplasia and cancer. Anticancer Res. 2015, 35, 523-530. [PubMed]

68. Sun, Y.; Yang, X.; Liu, M.; Tang, H. B4galt3 up-regulation by miR-27a contributes to the oncogenic activity in human cervical cancer cells. Cancer Lett. 2016, 375, 284-292. [CrossRef] [PubMed]

69. Yao, J.; Deng, B.; Zheng, L.; Dou, L.; Guo, Y.; Guo, K. MiR-27b is upregulated in cervical carcinogenesis and promotes cell growth and invasion by regulating CDH11 and epithelial-mesenchymal transition. Oncol. Rep. 2016, 35, 1645-1651. [CrossRef] [PubMed] 
70. Yamamoto, N.; Kinoshita, T.; Nohata, N.; Yoshino, H.; Itesako, T.; Fujimura, L.; Mitsuhashi, A.; Usui, H.; Enokida, H.; Nakagawa, M.; et al. Tumor-suppressive microRNA-29a inhibits cancer cell migration and invasion via targeting HSP47 in cervical squamous cell carcinoma. Int. J. Oncol. 2013, 43, 1855-1863. [PubMed]

71. Jia, W.; Wu, Y.; Zhang, Q.; Gao, G.E.; Zhang, C.; Xiang, Y. Expression profile of circulating microRNAs as a promising fingerprint for cervical cancer diagnosis and monitoring. Mol. Clin. Oncol. 2015, 3, 851-858. [CrossRef] [PubMed]

72. Kriegel, A.J.; Liu, Y.; Fang, Y.; Ding, X.; Liang, M. The miR-29 family: Genomics, cell biology, and relevance to renal and cardiovascular injury. Physiol. Genom. 2012, 44, 237-244. [CrossRef] [PubMed]

73. Gong, J.; Li, J.; Wang, Y.; Liu, C.; Jia, H.; Jiang, C.; Wang, Y.; Luo, M.; Zhao, H.; Dong, L.; et al. Characterization of microRNA-29 family expression and investigation of their mechanistic roles in gastric cancer. Carcinogenesis 2014, 35, 497-506. [CrossRef] [PubMed]

74. Li, Y.; Wang, F.; Xu, J.; Ye, F.; Shen, Y.; Zhou, J.; Lu, W.; Wan, X.; Ma, D.; Xie, X. Progressive miRNA expression profiles in cervical carcinogenesis and identification of HPV-related target genes for miR-29. J. Pathol. 2011, 224, 484-495. [CrossRef] [PubMed]

75. Chandrasekaran, K.S.; Sathyanarayanan, A.; Karunagaran, D. Downregulation of hmgb1 by miR-34a is sufficient to suppress proliferation, migration and invasion of human cervical and colorectal cancer cells. Tumour Biol. 2016, 37, 13155-13166. [CrossRef] [PubMed]

76. Li, J.; Yu, L.; Shen, Z.; Li, Y.; Chen, B.; Wei, W.; Chen, X.; Wang, Q.; Tong, F.; Lou, H.; et al. MiR-34a and its novel target, NLRC5, are associated with HPV16 persistence. Infect. Genet. Evol. 2016, 44, 293-299. [CrossRef] [PubMed]

77. Zhang, R.; Su, J.; Xue, S.L.; Yang, H.; Ju, L.L.; Ji, Y.; Wu, K.H.; Zhang, Y.W.; Zhang, Y.X.; Hu, J.F.; et al. HPV E6/p53 mediated down-regulation of miR-34a inhibits warburg effect through targeting ldha in cervical cancer. Am. J. Cancer Res. 2016, 6, 312-320. [PubMed]

78. Geng, D.; Song, X.; Ning, F.; Song, Q.; Yin, H. MiR-34a inhibits viability and invasion of human papillomavirus-positive cervical cancer cells by targeting E2F3 and regulating survivin. Int. J. Gynecol. Cancer 2015, 25, 707-713. [CrossRef] [PubMed]

79. Wang, J.H.; Zhang, L.; Ma, Y.W.; Xiao, J.; Zhang, Y.; Liu, M.; Tang, H. MicroRNA-34a-upregulated retinoic acid-inducible gene-i promotes apoptosis and delays cell cycle transition in cervical cancer cells. DNA Cell Biol. 2016, 35, 267-279. [CrossRef] [PubMed]

80. Orth, J.D.; Loewer, A.; Lahav, G.; Mitchison, T.J. Prolonged mitotic arrest triggers partial activation of apoptosis, resulting in DNA damage and p53 induction. Mol. Biol. Cell 2012, 23, 567-576. [CrossRef] [PubMed]

81. Schlereth, K.; Beinoraviciute-Kellner, R.; Zeitlinger, M.K.; Bretz, A.C.; Sauer, M.; Charles, J.P.; Vogiatzi, F.; Leich, E.; Samans, B.; Eilers, M.; et al. DNA binding cooperativity of p53 modulates the decision between cell-cycle arrest and apoptosis. Mol. Cell 2010, 38, 356-368. [CrossRef] [PubMed]

82. Airley, R.E.; Mobasheri, A. Hypoxic regulation of glucose transport, anaerobic metabolism and angiogenesis in cancer: Novel pathways and targets for anticancer therapeutics. Chemotherapy 2007, 53, 233-256. [CrossRef] [PubMed]

83. Bommer, G.T.; Gerin, I.; Feng, Y.; Kaczorowski, A.J.; Kuick, R.; Love, R.E.; Zhai, Y.; Giordano, T.J.; Qin, Z.S.; Moore, B.B.; et al. P53-mediated activation of miRNA34 candidate tumor-suppressor genes. Curr. Biol. CB 2007, 17, 1298-1307. [CrossRef] [PubMed]

84. Ji, Q.; Hao, X.; Zhang, M.; Tang, W.; Yang, M.; Li, L.; Xiang, D.; Desano, J.T.; Bommer, G.T.; Fan, D.; et al. MicroRNA miR-34 inhibits human pancreatic cancer tumor-initiating cells. PLoS ONE 2009, 4, e6816. [CrossRef] [PubMed]

85. Sun, F.; Fu, H.; Liu, Q.; Tie, Y.; Zhu, J.; Xing, R.; Sun, Z.; Zheng, X. Downregulation of CCND1 and CDK6 by miR-34a induces cell cycle arrest. FEBS Lett. 2008, 582, 1564-1568. [CrossRef] [PubMed]

86. Tarasov, V.; Jung, P.; Verdoodt, B.; Lodygin, D.; Epanchintsev, A.; Menssen, A.; Meister, G.; Hermeking, H. Differential regulation of microRNAs by p53 revealed by massively parallel sequencing: MiR-34a is a p53 target that induces apoptosis and G1-arrest. Cell Cycle 2007, 6, 1586-1593. [CrossRef] [PubMed]

87. Suzuki, H.I.; Yamagata, K.; Sugimoto, K.; Iwamoto, T.; Kato, S.; Miyazono, K. Modulation of microRNA processing by p53. Nature 2009, 460, 529-533. [CrossRef] [PubMed] 
88. Xin, J.X.; Yue, Z.; Zhang, S.; Jiang, Z.H.; Wang, P.Y.; Li, Y.J.; Pang, M.; Xie, S.Y. MiR-99 inhibits cervical carcinoma cell proliferation by targeting TRIB2. Oncology Lett. 2013, 6, 1025-1030.

89. Zhang, Y.; Liu, Y.; Yang, Y.X.; Xia, J.H.; Zhang, H.X.; Li, H.B.; Yu, C.Z. The expression of PLK-1 in cervical carcinoma: A possible target for enhancing chemosensitivity. J. Exp. Clin. Cancer Res. CR 2009, 28, 130. [CrossRef] [PubMed]

90. Li, B.H.; Zhou, J.S.; Ye, F.; Cheng, X.D.; Zhou, C.Y.; Lu, W.G.; Xie, X. Reduced miR-100 expression in cervical cancer and precursors and its carcinogenic effect through targeting PLK1 protein. Eur. J. Cancer 2011, 47, 2166-2174. [CrossRef] [PubMed]

91. Chen, D.; Chen, Z.; Jin, Y.; Dragas, D.; Zhang, L.; Adjei, B.S.; Wang, A.; Dai, Y.; Zhou, X. MicroRNA-99 family members suppress homeobox A1 expression in epithelial cells. PLoS ONE 2013, 8, e80625. [CrossRef] [PubMed]

92. Wilting, S.M.; van Boerdonk, R.A.; Henken, F.E.; Meijer, C.J.; Diosdado, B.; Meijer, G.A.; le Sage, C.; Agami, R.; Snijders, P.J.; Steenbergen, R.D. Methylation-mediated silencing and tumour suppressive function of hsa-miR-124 in cervical cancer. Mol. Cancer 2010, 9, 167. [CrossRef] [PubMed]

93. Hesselink, A.T.; Heideman, D.A.; Steenbergen, R.D.; Gok, M.; van Kemenade, F.J.; Wilting, S.M.; Berkhof, J.; Meijer, C.J.; Snijders, P.J. Methylation marker analysis of self-sampled cervico-vaginal lavage specimens to triage high-risk HPV-positive women for colposcopy. Int. J. Cancer 2014, 135, 880-886. [CrossRef] [PubMed]

94. Snellenberg, S.; de Strooper, L.M.; Hesselink, A.T.; Meijer, C.J.; Snijders, P.J.; Heideman, D.A.; Steenbergen, R.D. Development of a multiplex methylation-specific PCR as candidate triage test for women with an HPV-positive cervical scrape. BMC Cancer 2012, 12, 551. [CrossRef] [PubMed]

95. Harris, T.G.; Burk, R.D.; Yu, H.; Minkoff, H.; Massad, L.S.; Watts, D.H.; Zhong, Y.; Gange, S.; Kaplan, R.C.; Anastos, K.; et al. Insulin-like growth factor axis and oncogenic human papillomavirus natural history. Cancer Epidemiol. Biomark. Prev. 2008, 17, 245-248. [CrossRef] [PubMed]

96. Hirano, S.; Ito, N.; Takahashi, S.; Tamaya, T. Clinical implications of insulin-like growth factors through the presence of their binding proteins and receptors expressed in gynecological cancers. Eur. J. Gynaecol. Oncol. 2004, 25, 187-191. [PubMed]

97. Wan, H.Y.; Li, Q.Q.; Zhang, Y.; Tian, W.; Li, Y.N.; Liu, M.; Li, X.; Tang, H. MiR-124 represses vasculogenic mimicry and cell motility by targeting AMOTL1 in cervical cancer cells. Cancer Lett. 2014, 355, 148-158. [CrossRef] [PubMed]

98. Zhang, X.; Cai, D.; Meng, L.; Wang, B. Microrna-124 inhibits proliferation, invasion, migration and epithelial-mesenchymal transition of cervical carcinoma cells by targeting astrocyte-elevated gene- 1 . Oncol. Rep. 2016, 36, 2321-2328. [CrossRef] [PubMed]

99. Cui, F.; Li, X.; Zhu, X.; Huang, L.; Huang, Y.; Mao, C.; Yan, Q.; Zhu, J.; Zhao, W.; Shi, H. MiR-125b inhibits tumor growth and promotes apoptosis of cervical cancer cells by targeting phosphoinositide 3-kinase catalytic subunit delta. Cell. Physiol. Biochem. 2012, 30, 1310-1318. [CrossRef] [PubMed]

100. Wang, Y.D.; Cai, N.; Wu, X.L.; Cao, H.Z.; Xie, L.L.; Zheng, P.S. OCT4 promotes tumorigenesis and inhibits apoptosis of cervical cancer cells by miR-125b/bak1 pathway. Cell Death Dis. 2013, 4, e760. [CrossRef] [PubMed]

101. Fan, Z.; Cui, H.; Xu, X.; Lin, Z.; Zhang, X.; Kang, L.; Han, B.; Meng, J.; Yan, Z.; Yan, X.; et al. MiR-125a suppresses tumor growth, invasion and metastasis in cervical cancer by targeting Stat3. Oncotarget 2015, 6 , 25266-25280. [CrossRef] [PubMed]

102. Qin, X.; Wan, Y.; Wang, S.; Xue, M. MicroRNA-125a-5p modulates human cervical carcinoma proliferation and migration by targeting ABL2. Drug Des. Dev. Ther. 2016, 10, 71-79.

103. Ribeiro, J.; Marinho-Dias, J.; Monteiro, P.; Loureiro, J.; Baldaque, I.; Medeiros, R.; Sousa, H. MiR-34a and miR-125b expression in hpv infection and cervical cancer development. BioMed Res. Int. 2015, 2015, 304584. [CrossRef] [PubMed]

104. Song, X.; Shi, B.; Huang, K.; Zhang, W. MiR-133a inhibits cervical cancer growth by targeting EGFR. Oncol. Rep. 2015, 34, 1573-1580. [CrossRef] [PubMed]

105. Qin, W.; Dong, P.; Ma, C.; Mitchelson, K.; Deng, T.; Zhang, L.; Sun, Y.; Feng, X.; Ding, Y.; Lu, X.; et al. MicroRNA-133b is a key promoter of cervical carcinoma development through the activation of the ERK and AKT1 pathways. Oncogene 2012, 31, 4067-4075. [CrossRef] [PubMed] 
106. Bhattacharjya, S.; Roy, K.S.; Ganguly, A.; Sarkar, S.; Panda, C.K.; Bhattacharyya, D.; Bhattacharyya, N.P.; Roychoudhury, S. Inhibition of nucleoporin member Nup214 expression by miR-133b perturbs mitotic timing and leads to cell death. Mol. Cancer 2015, 14, 42. [CrossRef] [PubMed]

107. Sathyanarayanan, A.; Chandrasekaran, K.S.; Karunagaran, D. MicroRNA-146a inhibits proliferation, migration and invasion of human cervical and colorectal cancer cells. Biochem. Biophys. Res. Commun. 2016, 480, 528-533. [CrossRef] [PubMed]

108. Sun, X.; Sit, A.; Feinberg, M.W. Role of miR-181 family in regulating vascular inflammation and immunity. Trends Cardiovasc. Med. 2014, 24, 105-112. [CrossRef] [PubMed]

109. Ke, G.; Liang, L.; Yang, J.M.; Huang, X.; Han, D.; Huang, S.; Zhao, Y.; Zha, R.; He, X.; Wu, X. MiR-181a confers resistance of cervical cancer to radiation therapy through targeting the pro-apoptotic prkcd gene. Oncogene 2013, 32, 3019-3027. [CrossRef] [PubMed]

110. Chen, Y.; Ke, G.; Han, D.; Liang, S.; Yang, G.; Wu, X. MicroRNA-181a enhances the chemoresistance of human cervical squamous cell carcinoma to cisplatin by targeting PRKCD. Exp. Cell Res. 2014, 320, 12-20. [CrossRef] [PubMed]

111. Yang, L.; Wang, Y.L.; Liu, S.; Zhang, P.P.; Chen, Z.; Liu, M.; Tang, H. MiR-181b promotes cell proliferation and reduces apoptosis by repressing the expression of adenylyl cyclase 9 (AC9) in cervical cancer cells. FEBS Lett. 2014, 588, 124-130. [CrossRef] [PubMed]

112. Martinez-Velazquez, M.; Melendez-Zajgla, J.; Maldonado, V. Apoptosis induced by camp requires smac/diablo transcriptional upregulation. Cell Signal. 2007, 19, 1212-1220. [CrossRef] [PubMed]

113. Xu, H.; Zhu, J.; Hu, C.; Song, H.; Li, Y. Inhibition of microRNA-181a may suppress proliferation and invasion and promote apoptosis of cervical cancer cells through the PTEN/Akt/FOXO1 pathway. J. Physiol. Biochem. 2016, 72, 721-732. [CrossRef] [PubMed]

114. Liu, P.; Xin, F.; Ma, C.F. Clinical significance of serum miR-196a in cervical intraepithelial neoplasia and cervical cancer. Genet. Mol. Res. 2015, 14, 17995-18002. [CrossRef] [PubMed]

115. Zhang, J.; Zheng, F.; Yu, G.; Yin, Y.; Lu, Q. MiR-196a targets netrin 4 and regulates cell proliferation and migration of cervical cancer cells. Biochem. Biophys. Res. Commun. 2013, 440, 582-588. [CrossRef] [PubMed]

116. Liu, C.; Lin, J.; Li, L.; Zhang, Y.; Chen, W.; Cao, Z.; Zuo, H.; Chen, C.; Kee, K. Hpv16 early gene E5 specifically reduces miRNA-196a in cervical cancer cells. Sci. Rep. 2015, 5, 7653. [CrossRef] [PubMed]

117. Hou, T.; Ou, J.; Zhao, X.; Huang, X.; Huang, Y.; Zhang, Y. MicroRNA-196a promotes cervical cancer proliferation through the regulation of FOXO1 and p27Kip1. Br. J. Cancer 2014, 110, 1260-1268. [CrossRef] [PubMed]

118. Cao, Q.; Lu, K.; Dai, S.; Hu, Y.; Fan, W. Clinicopathological and prognostic implications of the miR-200 family in patients with epithelial ovarian cancer. Int. J. Clin. Exp. Pathol. 2014, 7, 2392-2401. [PubMed]

119. Cheng, Y.X.; Zhang, Q.F.; Hong, L.; Pan, F.; Huang, J.L.; Li, B.S.; Hu, M. MicroRNA-200b suppresses cell invasion and metastasis by inhibiting the epithelial-mesenchymal transition in cervical carcinoma. Mol. Med. Rep. 2016, 13, 3155-3160. [CrossRef] [PubMed]

120. Cheng, Y.X.; Chen, G.T.; Chen, C.; Zhang, Q.F.; Pan, F.; Hu, M.; Li, B.S. MicroRNA-200b inhibits epithelial-mesenchymal transition and migration of cervical cancer cells by directly targeting RhoE. Mol. Med. Rep. 2016, 13, 3139-3146. [CrossRef] [PubMed]

121. Zeng, F.; Xue, M.; Xiao, T.; Li, Y.; Xiao, S.; Jiang, B.; Ren, C. MiR-200b promotes the cell proliferation and metastasis of cervical cancer by inhibiting FOXG1. Biomed. Pharmacother. 2016, 79, 294-301. [CrossRef] [PubMed]

122. Bosse, G.D.; Simard, M.J. A new twist in the microRNA pathway: Not dicer but argonaute is required for a microRNA production. Cell Res. 2010, 20, 735-737. [CrossRef] [PubMed]

123. Nishikura, K. Editor meets silencer: Crosstalk between RNA editing and RNA interference. Nat. Rev. Mol. Cell Biol. 2006, 7, 919-931. [CrossRef] [PubMed]

124. Han, L.; Witmer, P.D.; Casey, E.; Valle, D.; Sukumar, S. DNA methylation regulates microRNA expression. Cancer Biol. Ther. 2007, 6, 1284-1288. [CrossRef] [PubMed]

125. Schwarz, D.S.; Hutvagner, G.; Du, T.; Xu, Z.; Aronin, N.; Zamore, P.D. Asymmetry in the assembly of the RNAi enzyme complex. Cell 2003, 115, 199-208. [CrossRef]

126. Kai, Z.S.; Pasquinelli, A.E. MicroRNA assassins: Factors that regulate the disappearance of miRNAs. Nat. Struct. Mol. Biol. 2010, 17, 5-10. [CrossRef] [PubMed] 
127. Martinez, I.; Gardiner, A.S.; Board, K.F.; Monzon, F.A.; Edwards, R.P.; Khan, S.A. Human papillomavirus type 16 reduces the expression of microRNA-218 in cervical carcinoma cells. Oncogene 2008, 27, 2575-2582. [CrossRef] [PubMed]

128. Luo, M.; Shen, D.; Wang, W.; Xian, J. Aberrant expression of microRNA-26b and its prognostic potential in human cervical cancer. Int. J. Clin. Exp. Pathol. 2015, 8, 5542-5548. [PubMed]

129. Yang, Y.; Song, K.L.; Chang, H.; Chen, L. Decreased expression of microRNA-126 is associated with poor prognosis in patients with cervical cancer. Diagn. Pathol. 2014, 9, 220. [CrossRef] [PubMed]

130. Yuan, Y.; Liu, B.; Xie, P.; Zhang, M.Q.; Li, Y.; Xie, Z.; Wang, X. Model-guided quantitative analysis of microRNA-mediated regulation on competing endogenous RNAs using a synthetic gene circuit. Proc. Natl. Acad. Sci. USA 2015, 112, 3158-3163. [CrossRef] [PubMed]

131. Salzman, D.W.; Nakamura, K.; Nallur, S.; Dookwah, M.T.; Metheetrairut, C.; Slack, F.J.; Weidhaas, J.B. MiR-34 activity is modulated through $5^{\prime}$-end phosphorylation in response to DNA damage. Nat. Commun. 2016, 7, 10954. [CrossRef] [PubMed] article distributed under the terms and conditions of the Creative Commons Attribution (CC BY) license (http:/ / creativecommons.org/licenses/by/4.0/). 